\title{
Quel est le rôle des protéines découplantes mitochondriales chez les mammifères et les oiseaux ?
}

\author{
M. DAMON', A. COLLIN² \\ 1 INRA, Agrocampus, UMR1079 Systèmes d'élevage, Nutrition animale et humaine, F-35590 Saint-Gilles, France \\ 2 INRA, UR83 Recherches Avicoles, F-37380 Nouzilly, France \\ Courriel : Marie.Damon@rennes.inra.fr
}

Les protéines découplantes sont des transporteurs mitochondriaux impliqués dans le métabolisme énergétique. Si 1'UCP1 est nécessaire à la survie du jeune mammifère au froid, les rôles des autres UCP sont encore controversés. Sont-elles impliquées dans la production de chaleur, les flux de nutriments ou encore dans la lutte contre la production de radicaux libres ?

C'est dans la mitochondrie, lieu où se déroulent et convergent de nombreuses voies métaboliques ( $\beta$ oxydation, cycle de Krebs, demi cycle de l'urée...) qu'est en grande partie synthétisé l'ATP (Adénosine TriPhosphate). Ainsi, les mitochondries sont les véritables moteurs de l'organisme car elles convertissent, au cours de la respiration cellulaire, l'énergie des aliments et réserves corporelles en ATP, énergie chimique disponible pour les processus nécessaires à la survie de l'organisme (maintien de gradients ioniques, synthèse protéique, contraction musculaire...). Cependant, le rendement de la respiration (ou l'efficacité respiratoire) n'est pas total et une partie de cette énergie est perdue sous forme de chaleur.

Les recherches menées en bioénergétique mitochondriale ont permis de mieux comprendre les mécanismes et la régulation de l'efficacité respiratoire. Les fuites de protons au travers de la Membrane Mitochondriale Interne (MMI) apparaissent comme une voie de régulation majeure de la respiration cellulaire. Une famille de protéines mitochondriales, appelées protéines découplantes (UCP pour UnCoupling Protein) pourrait être en partie responsable de ces fuites de protons. Ces UCP, mises en évidence dans les espèces animales et végétales et présentes dans de nombreux tissus, constitueraient une famille très ancienne mise en place par les organismes vivants pour moduler de manière universelle le métabolisme mitochondrial. De ce fait, elles pourraient intervenir dans de nombreuses situations physiopathologiques dans lesquelles la mitochondrie semble impliquée : diabète, obésité vieillissement, production de radicaux libres...

Avec plus de 6000 articles publiés depuis la découverte du premier membre de cette famille (UCP1) en 1976, ce domaine de recherche est dynamique et de nombreuses revues ont dernièrement été publiées sur ce sujet (Krauss et al 2005, Mozo et al 2005, Nübel et Ricquier 2006, Nicholls 2006, Wolkow et Iser 2006, Sluse et al 2006). Après un rappel de bioénergétique mitochondriale nécessaire à la compréhension des mécanismes et théories utilisés par la suite, cet article présentera la synthèse des résultats dernièrement obtenus concernant l'activité, la régulation ainsi que les hypothèses les plus récentes sur le rôle physiologique des UCP apparentées à 1'UCP1.

\section{1 / Bioénergétique mito- chondriale}

\section{1 / La phosphorylation oxyda- tive}

Selon la théorie chimiosmotique établie par Mitchell en 1966 (prix Nobel de chimie en 1978), l'énergie libre produite par l'oxydation des substrats dans la mitochondrie est conservée et convertie en un gradient électrochimique de protons (force proton motrice) au travers de la MMI (figure 1). Au cours des oxydations, le mouvement des électrons au sein de la MMI est guidé par les potentiels redox des complexes protéiques de la chaîne respiratoire (Complexe 1 à 4) et des 2 cofacteurs labiles (le coenzyme $Q$ et le cytochrome c). L'accepteur final d'électrons est l'oxygène qui est réduit en eau au niveau du complexe 4 (cytochrome c oxydase); c'est pourquoi l'oxydation mitochondriale est également appelée respiration cellulaire. Chacun de ces complexes, hormis le complexe II, couple le flux d'électrons avec un pompage des protons $\mathrm{H}^{+}$de la matrice vers l'espace inter membranaire, aboutissant en la création d'un gradient de concentration de protons de part et d'autre de la MMI. Ce gradient électrochimique $(\Delta \mathrm{p}$ ou force proton motrice) se compose d'une différence de potentiel membranaire $(\Delta \Psi))$ et d'une différence de $\mathrm{pH}(\Delta \mathrm{pH})$ entre la matrice et l'espace inter membranaire. L'énergie de ce gradient est utilisée par la F0F1 ATPase pour catalyser la réaction réversible de phosphorylation de l'ADP (Adénosine DiPhosphate) en ATP. La théorie chimiosmotique implique que la MMI soit imperméable aux protons (dans le cas contraire, le gradient généré par le pompage des protons se dissiperait au fur et à mesure).

La phosphorylation oxydative est définie comme le mécanisme réalisant le couplage entre la respiration cellulaire et la formation de groupes phosphates riches en énergie lors de la phosphorylation de l'ADP en ATP. L'efficacité stoechiométrique de la phosphorylation oxydative est définie par le ratio $\mathrm{P} / \mathrm{O}$ (i.e. la quantité de phosphate incorporé dans l'ATP par 
Figure 1. La phosphorylation oxydative et le découplage.

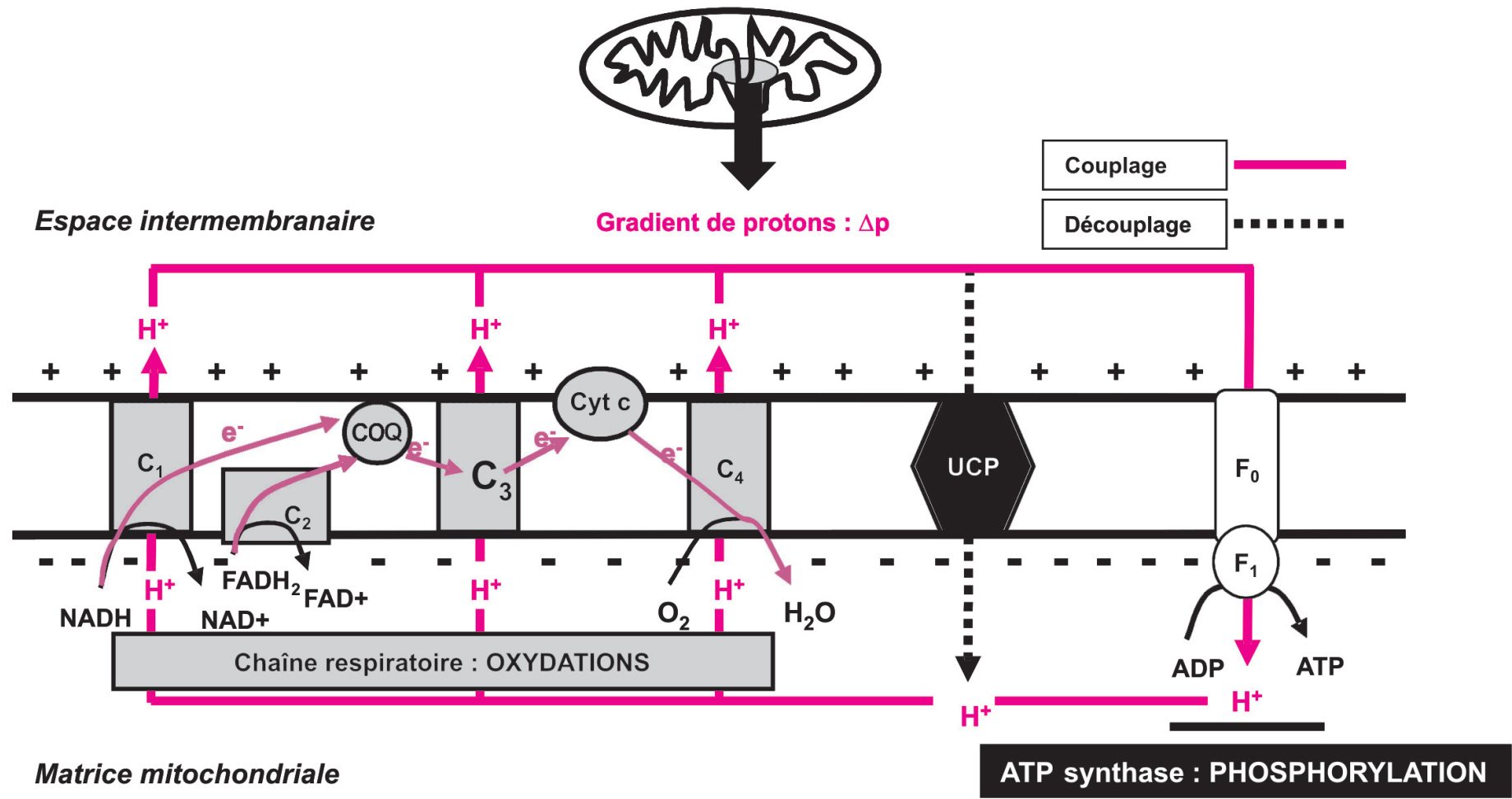

Une grande partie de l'énergie produite dans les voies cataboliques se retrouve contenue dans des coenzymes réduits (NADH et FADH2 (Flavoprotéine)) qui cèdent leurs deux électrons à la chaîne respiratoire qui par une cascade de réactions d'oxydo-réduction ( $\longrightarrow$ ), amène ces électrons jusqu'à l'accepteur final, l'oxygène moléculaire. Ces oxydations s'effectuent au travers des 4 complexes protéiques de la chaîne respiratoire: NADH-coenzyme Q oxydoréductase (C1), succinate-coenzyme Q oxydoréductase (C2), coenzyme Q-cytochrome c oxydoréductase (C3) et la cytochrome c oxydase (C4). Le coenzyme Q (COQ) et le cytochrome c (cyt c) sont eux des transporteurs mobiles de la chaîne respiratoire. Au niveau des complexes C1, C3 et C4, l'énergie d'oxydation est utilisée pour pomper des protons à travers la membrane de la matrice vers l'espace intermembranaire. Cette membrane étant imperméable aux protons, il s'établit un gradient de proton (ou force proton motrice), la matrice étant plus alcaline et négativement chargée que l'espace intermembranaire. Cette force proton motrice est utilisée pour la phosphorylation de l'ADP en ATP catalysée par l'ATP synthase. La respiration et la phosphorylation de l'ADP sont donc couplées via ce gradient de protons ( $\longrightarrow$ ). Les protéines découplantes (UCP) dissipent le gradient de protons au détriment de la synthèse d'ATP et l'énergie du gradient est alors perdue sous forme de chaleur. La respiration cellulaire (ou phosphorylation oxydative) est alors découplée ( - - - ).

molécule d'oxygène consommée), dont la valeur théorique fait encore l'objet de controverses (Brand 2005). Toutefois, une partie de la force proton motrice est dissipée sous forme de chaleur, notamment en raison de l'existence de mécanismes de découplage. Le découplage réduit l'énergie disponible pour les réactions métaboliques consommatrices d'ATP et diminue l'efficacité de la respiration mitochondriale mais il constitue une voie de modulation importante du métabolisme cellulaire en diminuant le potentiel de membrane ou en générant de la chaleur. De plus, l'existence du découplage est très importante dans le muscle où les besoins en ATP sont augmentés très rapidement lors de la contraction (x 100 lors d'une seule contraction), l'augmentation du seul flux oxydatif n'étant pas adaptée à une réaction aussi rapide et d'une telle ampleur (Boss et al 2000).

\section{2 / Le découplage}

La phosphorylation oxydative repose sur l'établissement d'une force proton motrice $\Delta p$ qui permet la synthèse d'ATP. En conséquence, toute diminution de $\Delta \mathrm{p}$ non liée à cette synthèse d'ATP découple l'oxydation de la phosphorylation. Le rapport de sa mesure de la respiration mitochondriale en présence d'ADP (Etat 3, phosphorylation active) sur la mesure de la respiration mitochondriale en absence d'ADP (Etat 4, phosphorylation inactive) est un indice de couplage appelé Indice du Contrôle Respiratoire (ICR). Le découplage peut être provoqué par une diminution du nombre de protons pompés au travers de la MMI par les complexes de la chaîne respiratoire (patinage des pompes à protons ou découplage intrinsèque, Azzone et al 1985) ou par l'existence de fuites de protons qui dissipent le $\Delta \mathrm{p}$ au détriment de la synthèse d'ATP (découplage extrinsèque).

Le découplage intrinsèque repose sur un «patinage» des pompes à protons, c'est-à-dire sur une diminution de l'efficacité du pompage des protons par les complexes de la chaîne respiratoire qui résulte en une diminution de la stoechiométrie $\mathrm{H}^{+} / \mathrm{e}^{-}$(diminution du couplage entre le transport des électrons et la translocation des protons) (Azzone et al 1985). Ce patinage semble avoir lieu à des valeurs élevées du potentiel de membrane, au niveau des complexes 3 et 4 mais également au niveau de F0-F1-ATPase mais il n'a jamais été mis en évidence au niveau du complexe 1 (Brand 2005). Cependant, l'existence de ce patinage in vivo est controversée (Kadenbach 2003, Brand 2005) et un découplage extrinsèque semble plus probable (Nicholls 2006).

Le découplage extrinsèque ou dissipation futile du gradient de protons au travers de la MMI est également appelé fuite de protons. Il consiste en un retour des protons de l'espace inter membranaire vers la matrice mitochondriale sans synthèse d'ATP. La relation entre la fuite de protons et la force proton motrice ne suit pas la loi d'Ohm de sorte que la fuite de protons aug- 
mente de façon exponentielle lorsque la force proton motrice augmente linéairement. Cette fuite de protons est physiologiquement importante et constitue une voie de régulation majeure de l'énergétique mitochondriale (Brand et al 1999). Elle représente 20 à $30 \%$ de la consommation d'oxygène d'hépatocytes isolés et jusqu'à $50 \%$ de la consommation basale d'oxygène d'un muscle perfusé (Rolfe et Brand 1996). Chez le rat, en tenant compte de la contribution de tous les tissus, les fuites de protons pourraient représenter 20 à $25 \%$ du métabolisme de repos. De plus, si l'on se situe dans un état actif (production d'ATP) ces fuites de protons contribuent encore pour $15 \%$ au métabolisme. En dehors de l'action bien connue de découplants chimiques et des acides gras, on distingue la fuite de protons basale (ou non spécifique) de la fuite de protons inductible (ou régulée).

\section{3 / Les découplants chimiques et les acides gras}

Les acides gras et les composés chimiques aromatiques comme le 2,4 dinitrophénol (DNP) et le carbonyl cyanide p-trifluoromethoxyphenylhydrazone (FCCP) augmentent la perméabilité de la MMI aux protons en facilitant le passage des $\mathrm{H}^{+}$à travers la bicouche lipidique hydrophobe via un cycle futile (McLaughin et Dilger 1980) (figure 2.1). En effet, ces composés chimiques sont capables de traverser la MMI sous leur forme protonée ou dissociée du fait de la répartition de la charge sur le noyau aromatique. De ce fait, la forme protonée traverse la MMI. Dans la matrice plus alcaline, le composé se dissocie et l'anion est expulsé dans l'espace inter membranaire indépendamment du potentiel de membrane. En revanche la forme anionique des acides gras traverse difficilement la MMI. L'action découplante des acides gras s'effectue uniquement lorsque le potentiel de membrane est suffisamment élevé pour permettre la translocation des anions de la matrice (chargée négativement) vers l'espace inter membranaire (chargé positivement) (Skulachev 1991). Ce cycle futile se répète jusqu'à ce que le $\Delta \mathrm{p}$ soit complètement dissipé. Il pourrait être augmenté par la présence d'un transporteur protéique de la forme anionique (figure 2.2).

\section{4 / La fuite de protons basale}

L'origine de la perméabilité basale de la MMI aux protons, ou fuite de protons, présente dans toutes les mitochondries et contribuant au métabolisme de repos, mais insensible à l'action d'activateurs ou d'inhibiteurs, est encore très mal connue. Cette fuite de protons basale pourrait être importante physiologiquement car elle limiterait la production d'espèces actives de l'oxygène $(E A O)$ : c'est la théorie d'un découplage physiologique léger ou «mild uncoupling».

Les lipides étant les constituants majeurs de la MMI (50\%), il a donc tout d'abord été suggéré qu'ils pourraient être responsables de cette fuite de protons basale. Une forte corrélation entre la perméabilité basale et la composition lipidique de la MMI est rapportée avec une perméabilité accrue lorsque la MMI contient des acides gras polyinsaturés et plus faible avec des acides gras monoinsaturés. Cependant, la fuite de protons de liposomes reconstitués à partir de lipides mitochondriaux ne représente que 2 à $25 \%$ de celle des mitochondries dont ils sont issus et elle n'est pas modifiée lorsque la composition lipidique change

Figure 2. Les fuites de protons mitochondriales.

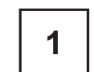

Espace intermembranaire

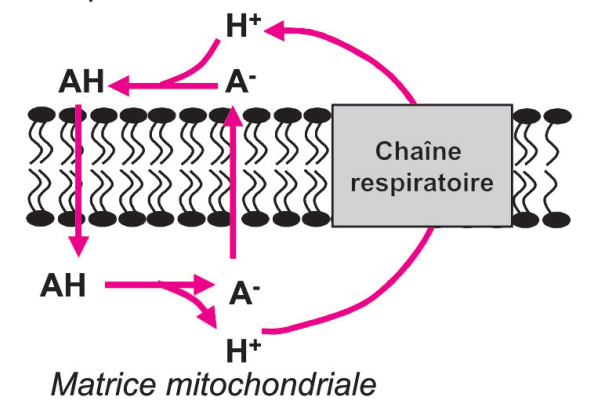

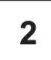

Espace intermembranaire

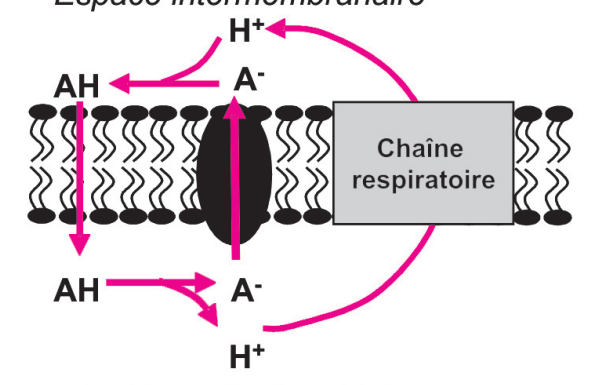

Matrice mitochondriale
1/ Effet des acides gras et des découplants chimiques ;

2/ Transporteur anionique.
(Brookes et al 1997). Ces auteurs estiment que les lipides membranaires n'expliqueraient que $5 \%$ de la fuite de protons basale.

Les recherches s'orientent maintenant vers des protéines de la MMI qui seraient responsables de la fuite de protons basale. Roussel et al (2002) ont réalisé chez la levure l'invalidation de 21 gènes de la famille des transporteurs d'anions mitochondriaux sans observer de modification significative du découplage. En revanche, une étude récente (Brand et al 2005) montre par des expériences de transgenèse (ablation, sous ou surexpression de l'adénine translocase, ANT (Adénine translocase), que 50 à $75 \%$ des fuites de protons basales seraient liées à la quantité d'ANT présente dans la MMI, indépendamment de son activité de transporteur des nucléotides phosphates (ADP et ATP).

En revanche, la contribution d'une autre protéine mitochondriale, la protéine découplante UCP1 (cf ci-dessous) au découplage basal est encore largement débattue. Jimenez-Jimenez et al (2006) montrent dans des levures qu'une double mutation sur ce gène (Glu134Asp et Met140Phe) modifie le découplage basal en obturant un canal protonique mais n'empêchent pas la stimulation d'UCP1 par les acides gras via un mécanisme non encore établi. Cependant, si on inhibe l'activité d'UCP1 chez des souris normales, le transport de protons est alors identique à celui de souris dont le gène UCP1 est invalidé. La quantité de protéines UCP1 dans la MMI ne permet donc pas de rendre compte de l'existence d'une fuite de protons basale (Brand et al 2005).

\section{5 / La fuite de protons régulée}

Dans la fuite de protons régulée, une protéine de la MMI catalyserait le transfert de protons de l'espace membranaire vers la matrice mitochondriale et serait responsable de l'augmentation de la perméabilité de la MMI aux protons. Les protéines découplantes qui font l'objet de cette synthèse seraient les principaux médiateurs de cette fuite de protons régulée. Cependant, d'autres protéines ont été impliquées dans la régulation de la respiration cellulaire via les fuites de protons (Kadenbach 2003, Brand 2005, Starkov 2006). Parmi ces médiateurs protéiques on trouve : l'ANT (Brustovetsky et al 1990), le transporteur aspartate/glutamate, des transporteurs impliqués dans un cycle futile de calcium (Skulachev 1999). Toutes ces réactions possèdent des propriétés communes : 
$1 /$ ces protéines catalysent la translocation des protons de l'espace inter membranaire vers la matrice,

2/ des cofacteurs sont nécessaires pour activer le découplage,

3/ la réaction est activée par les acides gras,

4/ la réaction est inhibée par les nucléotides phosphates,

5/ les mécanismes biochimiques mis en jeu sont encore largement méconnus.

\section{2 / Les protéines décou- plantes}

\section{1 / L'UCP1 : le début d'une longue histoire}

\section{a) Mise en évidence}

C'est dans le cadre de recherches menées sur la thermogenèse (production de chaleur) au froid dans le TAB (Tissu Adipeux Brun) que la première protéine découplante (UCP1) a été découverte. En effet, le TAB est un organe thermogénique particulièrement actif chez les mammifères nouveaux nés, les rongeurs non hibernants exposés au froid ainsi que chez les animaux hibernants lors du réveil. Il est constitué d'adipocytes particuliers distincts morphologiquement et fonctionnellement des adipocytes du tissu adipeux blanc. La couleur brune de ce tissu est d'ailleurs liée à sa richesse exceptionnelle en mitochondries. Les adipocytes bruns contiennent également de nombreuses gouttelettes de triglycérides tandis que les adipocytes blancs matures se caractérisent par une seule grosse vacuole. En absence d'albumine sérique bovine (BSA, chélateur d'acides gras), les mitochondries du TAB sont naturellement découplées de telle sorte que la totalité de l'énergie des oxydations est dissipée sous forme de chaleur. Le TAB est un tissu extrêmement vascularisé ce qui permet à la fois un apport important de substrats et d'oxygène mais également une bonne diffusion de la chaleur produite dans tout l'organisme.

C'est en 1974 que Nicholls a montré qu'en absence de BSA (en condition de découplage par les acides gras), une concentration importante de GDP (Guanosine DiPhosphte de l'ordre du $\mathrm{mM}$ ) était capable d'inhiber le découplage de mitochondries isolées du TAB. De plus, une concentration beaucoup plus faible $(10 \mu \mathrm{M})$ de GDP permettait d'inhiber $50 \%$ du découplage en pré- sence de BSA (c'est à dire sans effet découplant des acides gras). Nicholls a alors émis l'hypothèse qu'une protéine inhibée par le GDP était impliquée dans la régulation de la perméabilité de la MMI aux protons. La protéine nommée «thermogénine» puis UCP1 a été identifiée, purifiée et clonée entre 19761986 (Ricquier et Kader 1976, Lin et Klingenberg 1980, Bouillaud et al 1985 et 1986, Aquila et al 1985). Suite à ces études moléculaires, le rôle d'UCP1 dans la production chaleur au froid a été conforté par des manipulations génétiques d'invalidation du gène chez la souris qui montraient que ces souris invalidées étaient incapables de maintenir leur température corporelle et mourraient si elles étaient exposées à $4^{\circ} \mathrm{C}$ (Enerback et al 1997).

En dépit du rôle clairement établi pour l'UCP1 dans la thermogenèse, les mécanismes biochimiques du découplage ne sont pas encore totalement caractérisés. Il est généralement admis que les acides gras activent le découplage tandis que les nucléotides phosphate (ADP, ATP, GDP et GTP) l'inhibent. Afin d'expliquer l'absence de découplage dans des modèles reconstitués (liposomes), il a été suggéré que d'autres cofacteurs étaient nécessaires pour l'activation d'UCP1 comme le coenzyme Q (Echtay et al 2000), l'anion superoxyde $\left(\mathrm{O}_{2}{ }^{-}\right.$, Echtay et al 2002), des produits de péroxydation lipidique comme le 4-hydroxy-2-nonenal (HNE, Echtay et al 2005) ou les rétinoïdes (Rial et al 1999, Tomas et al 2004). Deux modèles concurrents de mécanisme d'action ont été proposés pour l'UCP1 : canal protonique et transport d'acides gras (Breen et al 2006, Rial et al 2004). Dans ces 2 modèles, les acides gras sont des activateurs indispensables du transport $\mathrm{d}^{\prime} \mathrm{H}^{+}$catalysé par UCP1 dans les mitochondries. Cependant, cette idée est encore débattue (Shabalina et al 2004).

\section{b) Le mécanisme de la thermogenèse} dans le TAB

La régulation de la thermogenèse dans le TAB (figure 3 ) est établie depuis longtemps (Nicholls et Locke 1984). Ce mécanisme de production de chaleur est clairement sous le contrôle de l'activité nerveuse sympathique. Lors d'une exposition au froid, l'hypothalamus secrète de la noradrénaline qui se lie sur des récepteurs $\beta$-adrénergiques provoquant la libération d'AMPc. Ce messager intracellulaire va induire via la voie de phosphorylation de la protéine kinase A, l'activation de la lipolyse, la transcription
d'UCP1 et du PPAR $\gamma$ coactivateur 1 (PGC1) qui lui-même stimule la biogenèse mitochondriale. En parallèle, la voie $\beta$-adrénergique stimulerait l'activité déiodinase qui convertit la thyroxine $\mathrm{T}_{4}$ en triiodothyronine $\mathrm{T}_{3}$. Cette hormone se lierait à son récepteur intracellulaire et activerait sur la zone promotrice du gène UCP1 un élément de réponse à la $\mathrm{T} 3$ (TRE) qui régule la transcription du gène (Silva et Rabelo 1997). Les acides gras libérés par la stimulation de la lipolyse agissent comme des substrats oxydatifs qui activent l'UCP1 au niveau biochimique mais également au niveau transcriptionnel provoquant une augmentation de chaleur du fait d'un découplage respiratoire. Quand la stimulation hormonale cesse, la lipolyse est inhibée et l'UCP1 est de nouveau inhibée par les nucléotides phosphates.

\section{2 / Une famille de protéines découplantes}

Comme le découplage respiratoire n'est pas spécifique du TAB, l'hypothèse de l'existence de protéines homologues de l'UCP1 a été suggérée et a conduit à partir de 1997, à l'identification de plusieurs protéines apparentées aussi bien chez les animaux (tableau 1) que chez les végétaux. Aujourd'hui les UCP forment une famille de protéines membranaires intra mitochondriales composée de 7 membres chez les mammifères (UCP1 à 5, KMCP1 et HDMCP) et d'avUCP (Protéine découplante aviaire) chez les oiseaux. On remarque de fortes similarités entre les UCP1, UCP2 et UCP3 (tableau 1) qui seraient assez proches phylogénétiquement (cf ci-dessous).

Ces protéines de la MMI possèdent environ 300 acides aminés pour un poids moléculaire d'approximativement $34 \mathrm{kDa}$. Ce sont des protéines basiques avec un point isoélectrique de 9. La suite de cet article sera essentiellement consacrée aux UCP exprimées dans le muscle : UCP2, UCP3 et avUCP.

\section{a) La superfamille des transporteurs} anioniques mitochondriaux

Les protéines découplantes appartiennent à la famille des transporteurs mitochondriaux (Ledesma et al 2002, Palmieri 2004, Arco et Satrustegui 2005) qui inclue notamment les échangeurs aspartate/glutamate, le transporteur de dicarboxylate, ANT et les transporteurs de phosphate, pyruvate et malate. Cette famille (SLC25, Solute Carrier family 25 chez l'homme) comp- 
Figure 3. Le mécanisme de la thermogénèse dans la mitochondrie du TAB.

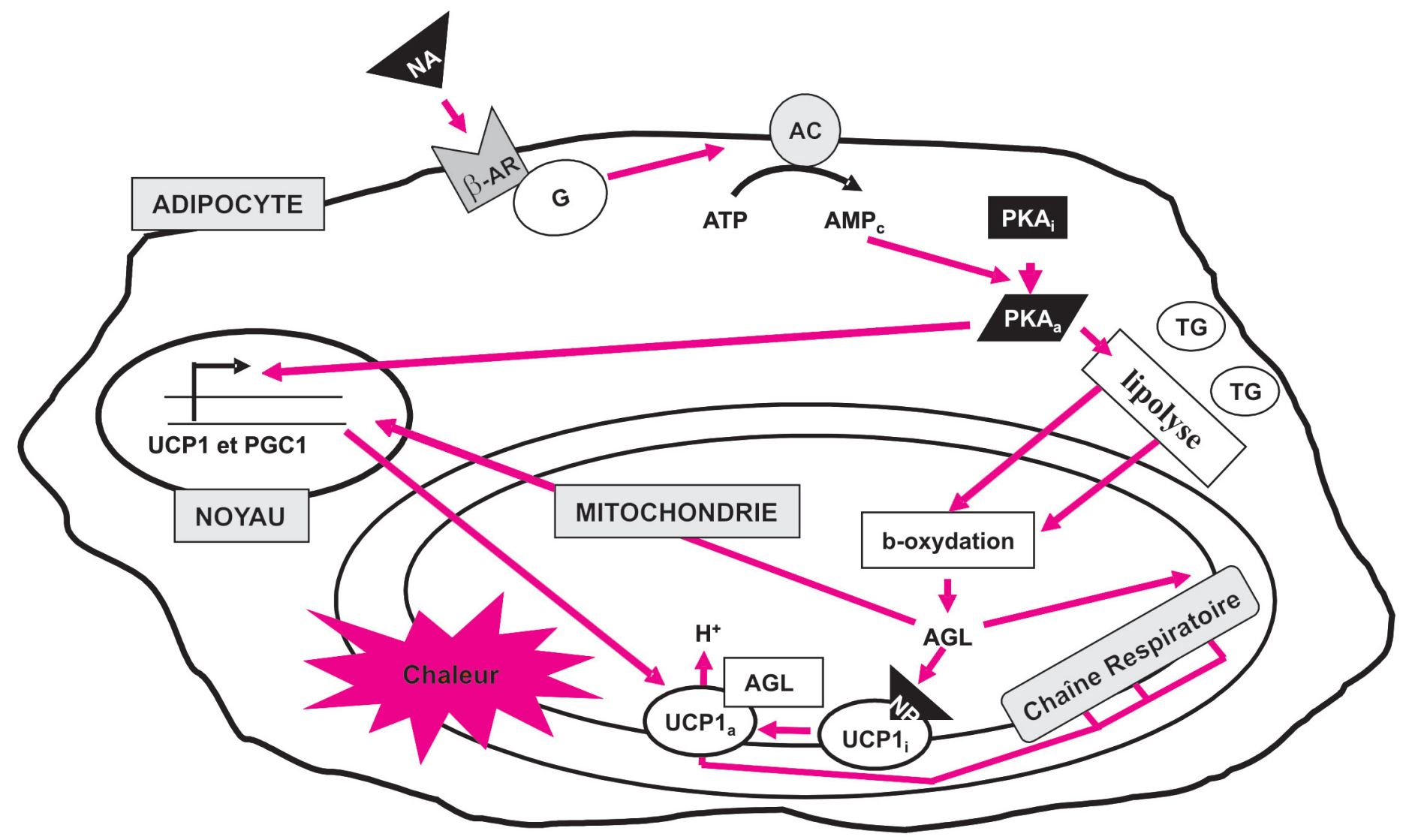

$N A$, noradrénaline ; $\beta A R$, récepteur $\beta$-adrénergique ; $G$, protéine $G$; $A C$, adenylate cyclase ; PKAi protéine kinase $A$ inactive ; PKAa protéine kinase A active ; AGL, acide gras libre; NP, nucléotide phosphate ; UCP1i , UCP1 inactive ; UCP1a , UCP1 active ; PGC1, PPAR g like coactivator 1 ; $\rightarrow$ activation.

Tableau 1. Protéines découplantes animales.

\begin{tabular}{|c|c|c|c|c|}
\hline $\begin{array}{c}\text { Gène } \\
\text { (première } \\
\text { publication) }\end{array}$ & $\begin{array}{l}\text { Localisation } \\
\text { chromosomique } \\
\text { (homme) }\end{array}$ & $\begin{array}{c}\% \\
\text { homologie }\end{array}$ & $\begin{array}{l}\text { Localisation } \\
\text { tissulaire }\end{array}$ & $\begin{array}{l}\text { Quantité } \\
\text { (\% des protéines } \\
\text { mitochondriales) }\end{array}$ \\
\hline $\begin{array}{c}\text { UCP1 } \\
\text { (Ricquier et Kader } \\
1976) \\
\end{array}$ & $4 q 31$ & & $\begin{array}{c}\text { TAB } \\
\text { Muscle lisse } \\
\text { thymus } \\
\end{array}$ & $\begin{array}{c}5-8 \% \\
\text { Au froid }\end{array}$ \\
\hline $\begin{array}{c}\text { UCP2 } \\
\text { (Fleury et al 1997) }\end{array}$ & $11 q 13$ & $59 \%$ UCP1 & $\begin{array}{l}\text { Ubiquitaire } \\
\text { sauf foie }\end{array}$ & $0,03 \%$ \\
\hline $\begin{array}{c}\text { UCP3 } \\
\text { (Boss et al 1997) }\end{array}$ & $11 q 13$ & $57 \%$ UCP1 & Muscle & $0,01 \%$ \\
\hline $\begin{array}{c}\text { UCP4 } \\
\text { (Mao et al 1999) }\end{array}$ & $6 p 11,2-q 12$ & $30 \%$ UCP1 & Cerveau & ND \\
\hline $\begin{array}{c}\text { UCP5 } \\
\text { (Sanchis et al } \\
1998 \text { ) }\end{array}$ & $\mathrm{Xq24}$ & $33 \%$ UCP1 & Cerveau & ND \\
\hline $\begin{array}{c}\text { HDMCP } \\
\text { (Tan et al 2004) }\end{array}$ & $14 q 32,31$ & $25 \%$ UCP1 & $\begin{array}{l}\text { Carcinome } \\
\text { hépatique }\end{array}$ & ND \\
\hline $\begin{array}{c}\text { KMCP1 } \\
\text { (Hagenauer et al } \\
2005) \\
\end{array}$ & $13 q 14,11$ & $80 \%$ UCP5 & Rein & ND \\
\hline $\begin{array}{c}\text { UCP6 } \\
\text { (Sokolova et } \\
\text { Sokolov 2005) } \\
\end{array}$ & $\begin{array}{l}\text { Clonée chez } \\
\text { l'huître }\end{array}$ & $\begin{array}{l}45-49 \% \\
\text { UCP2 et } \\
\text { UCP3 }\end{array}$ & ND & ND \\
\hline $\begin{array}{c}\text { avUCP } \\
\text { (Raimbault et al } \\
\text { 2001) }\end{array}$ & ND & $55 \%$ UCP1 & $\begin{array}{l}\text { Muscle et } \\
\text { Coeur }\end{array}$ & ND \\
\hline
\end{tabular}

ND : non déterminé. 
rend des protéines localisées dans la MMI qui catalysent la translocation de métabolites au travers de cette membrane. Elles contrôlent la perméabilité de la MMI et assurent une liaison métabolique entre le cytosol et la mitochondrie. La majorité des composés transportés sont des anions mais certaines transportent également des cations. La taille des substrats varie de substrats très petits comme les protons à de larges molécules chargées, la plus importante étant l'ATP. Ces protéines sont des homodimères constitués de monomères possédant tous la même structure : 3 domaines d'environ 100 résidus formés par 2 régions hydrophobes ( 2 hélices $\alpha$ ) reliées entre elles par des segments hydrophiles (figure 4). La séquence P-X-[DE]-X[LIVAT]-[RK]-X-[LRH]-[LIVMFY][QGAIVM] appelée signature protéique de transfert d'énergie, est désormais utilisée pour caractériser les nouveaux membres de cette super famille.

Arechaga et al (2001) suggèrent que les hélices $\alpha$ aménagent un canal hydrophile au sein du transporteur tandis que les secteurs hydrophiles forment des portes qui assurent la sélectivité du transporteur.

\section{b) Phylogénie}

Les UCP possèdent une distribution phylogénique très vaste puisqu'on les retrouve chez des insectes, des poissons, des mammifères, des oiseaux et même dans le règne végétal. Ceci suggère que les UCP forment une famille très ancienne et conservée et que le découplage est une stratégie universelle mise en place par les organismes vivants pour moduler l'efficacité du métabolisme énergétique. En 2005, 51 protéines découplantes de plantes et de mammifères ont été regroupées dans 5 familles (Nogueira et al 2005). La famille 1 regroupait les UCP1 à 3, les familles 2 et 5 étaient constituées uniquement d'UCP végétales, la famille 3 contenait l'UCP4, une UCP végétale et l'UCP de Caenorhabditis elegans et la famille 4 contenait uniquement par 1'UCP5. Une autre étude suggére que 1'UCP4 soit la forme la plus proche de l'UCP ancestrale (Hanak et Jezek 2001). La localisation exclusive d'UCP4 dans le cerveau suggère une fonction très spécifique pour ce gène ce qui est très surprenant pour un gène ancestral. Une analyse phylogénétique à partir d'homologues des UCP2, UCP3 et UCP5 dans le génome d'invertébrés à l'aide d'amorces dégénérées remet d'ailleurs en cause ce résultat (Sokolova et Sokolov 2005). La divergence entre les UCP serait très ancienne ce qui suggère une différenciation fonctionnelle de cette famille de gènes qui se répartit en 3 classes : une première classe contenant UCP6 (nouvelle UCP d'invertébré), UCP1, UCP2 et UCP3 ; une seconde classe contenant 1'UCP4 et une troisième classe contenant l'UCP5. Le gène UCP6 mis en évidence chez l'huître (45-49 \% de similitudes avec les protéines UCP2 et $\mathrm{UCP} 3$ ) serait le gène ancestral des UCP1, UCP2 et UCP3.

\section{3 / Les gènes}

\section{a) UCP1}

Ce gène est abondamment exprimé dans le TAB où la protéine pourrait représenter 5-8 \% des protéines mitochondriales. Des études récentes montrent que l'expression de cette protéine n'est pas restreinte au TAB comme il fut longtemps admis. En effet, elle serait également exprimée dans le thymus (Caroll et al 2005) et les muscles lisses (Nibbelink et al 2002, Porter 2006). Le gène UCP1 se trouve chez

Figure 4. Topologie des protéines de transport mitochondriales.

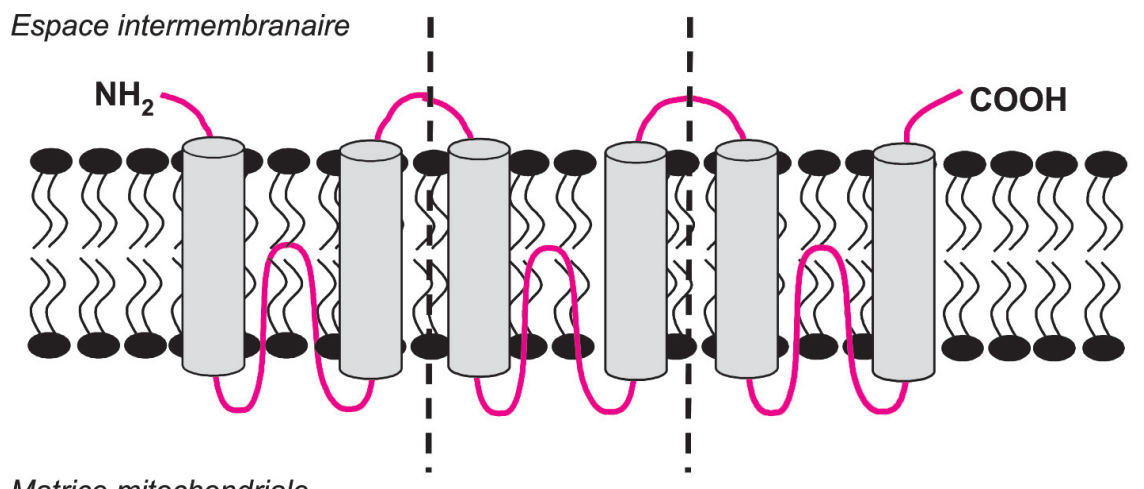

Matrice mitochondriale

Ces protéines comportent 3 domaines similaires formés par 2 régions hydrophobes (hélices- $\alpha, 0$ ) reliées entre elles par des segments hydrophiles dont le second pénètre dans la membrane $\left(^{-}\right)$. Les lignes pointillées séparent les 3 domaines.

l'homme sur le chromosome 4 q31 (sur le chromosome 8 chez la souris). Il est constitué de 6 exons qui couvrent environ $9 \mathrm{~kb}$, chacun codant pour l'une des hélices $\alpha$. La régulation d'UCP1 s'effectue comme nous l'avons vu à 2 niveaux : au niveau de l'activité de la protéine (acides gras et nucléotides phosphates notamment) ou au niveau de la transcription. Le promoteur d'UCP1 contiendrait des éléments de réponse à l'AMPc (Adénosine diphosphate) (CRE, Boyer et Kozak 1991), aux PPAR $\alpha, \beta$ et $\gamma$ (PPRE, Barbera et al 2001, Sears et al 1996, Wang et al 2003). L'insuline, la triiodothyronine et l'acide rétinoïque (Cassard-Doulcier et al 1994, Lanni et al 2003) activent également la transcription d'UCP1 mais les mécanismes ne sont pas encore totalement établis.

\section{b) $U C P 2$}

L'UCP2, le premier homologue identifié, possède l'expression tissulaire la plus étendue de cette famille de gènes : majoritairement exprimée dans le TAB mais également dans le tissu adipeux, le muscle, le cœur, la rate, le poumon, l'estomac, le rein (Fleury et al 1997). Cependant la plupart des études réalisées portent sur l'expression des ARNm (Acide RiboNucléique) (remarque également valable pour l'UCP3). Il faut donc tenir compte de l'absence de corrélation entre le taux d'ARNm et la quantité de protéine détectée. Ainsi, à l'aide d'anticorps développés dans leur laboratoire, Pecqueur et al (2001) ont révélé l'absence de la protéine dans le cœur, le muscle et le TAB des souris. Le gène UCP2 se trouve sur le chromosome 11 q13 (chromosome $7 \mathrm{chez}$ la souris) très proche de l'UCP3 puisque ces 2 gènes se trouvent sur une même portion de $150 \mathrm{~Kb}$. Des analyses de polymorphisme ont montré que cette région pouvait être impliquée dans le développement de pathologies comme l'hyper insulinémie et l'obésité (Fleury et al 1997). Le gène UCP 2 contient 8 exons et 7 introns ; il couvre une région de $8,7 \mathrm{~kb}$. Il possède une homologie en acides aminés de $55 \%$ avec l'UCP1 et $71 \%$ avec 1'UCP3. Des liaisons intron/exon très conservées par rapport aux gènes UCP1 et UCP3 et la colocalisation chromosomique d'UCP2 et d'UCP3 suggèrent que ces gènes sont issus d'évènements de duplication ( $\mathrm{Tu}$ et al 1999). Récemment, un deuxième transcrit issu de l'épissage alternatif de l'UCP2 a été mis en évidence dans des tumeurs osseuses (Srivastava et al 2006). Ce transcrit code pour une protéine courte de 79 acides aminés car 
une insertion de 22 nucléotides dans l'intron 3 introduit un codon stop dans l'exon 4. Yoshitomi et al (1999) ont recherché les éléments de réponse présents dans la région promotrice d'UCP2. Le promoteur contiendrait notamment des éléments de réponse à 1'AMPc (2 CRE), MyoD (E-box), aux glucocorticoïdes (GRE), PPAR (PRE). De plus, ce gène pourrait être régulé au niveau de la traduction car il existe un deuxième cadre de lecture ouvert dans l'exon 2 qui inhibe la traduction de l'UCP2 (cadre de lecture ouvert dans l'exon 3, Pecqueur et al 2001).

\section{c) $U C P 3$}

L'UCP3 (Schrauwen et al 2006a) est majoritairement exprimée dans le muscle mais l'ARNm est détecté également dans TAB, le tissu adipeux et le cœur (Boss et al 1997). De plus, si l'on considère le type métabolique des muscles, l'UCP3 est d'avantage exprimée dans les muscles glycolytiques que dans les muscles oxydatifs (Jimenez et al 2002, Hesselink et al 2001). Certaines études montrent également une expression plus importante d'UCP3 dans les mitochondries subsarcolemmales par rapport aux mitochondries intramyofibrillaires (Jimenez et al 2002). Cependant, aucune différence de fuite de protons n'a pu être observée entre ces 2 types de mitochondries (Lombardi et al 2000).

Le gène UCP3 humain contient 7 exons dont 6 exons codants et couvre une région de $8,5 \mathrm{~Kb}$. Il génère 2 transcrits : un court (UCP3S 275 acides aminés) et un long (UCP3L 312 acides aminés) qui proviennent d'un épissage alternatif au niveau de l'exon 6 (Solanes et al 1997). Trente sept acides aminés différencient ces 2 transcrits. Cette transcription alternative aurait lieu dans la moitié des cas de sorte que les 2 transcrits sont exprimés dans le muscle en proportion égale. Cette partie C-terminale présente une forte similarité avec une région de l'UCP1 comportant un site d'inhibition par les nucléotides. Il semble également que la délétion de cette séquence soit importante pour le positionnement correct de la protéine dans la bicouche lipidique de la MMI puisqu'elle correspond à une partie du sixième segment transmembranaire de la protéine. Cependant, la perte d'activité due à cette éventuelle instabilité pourrait être compensée par la perte de l'inhibition par les nucléotides (Millet et al 1998, Boss et al 1997).

Plusieurs motifs de reconnaissance spécifiques de facteurs de transcription musculaires ont été identifiés dans la région promotrice du gène : $\mathrm{E}$ box (MyoD), MEF2 (muscle enhancer factor 2) et une boîte CCAC ( Tu et al 2000). La région promotrice contient également des éléments de réponse pour l'acide rétinoïque (Acin et al 1999), les PPAR $\alpha$ et $\delta$ (Solanes et al 2003), les hormones thyroïdiennes (Solanes et al 2005) et l'AMPc (Acin et al 1999). La stimulation de l'activité de 1'UCP3 par les rétinoïdes est cependant controversée (Mozo et al 2006).

\section{d) UCP4, UCP5, KMCP1 et HDMCP}

Il y a actuellement très peu de données sur ces protéines qui possèdent une homologie beaucoup moins forte avec l'UCP1 (25 à $30 \%$ ) que l'UCP2 et 1'UCP3.

L'UCP4 clonée en 1999 est exprimée exclusivement dans le cerveau et localisée sur le chromosome 6p11.2q12 humain (Mao et al 1999). Elle serait impliquée dans l'apoptose neuronale (Ho et al 2005). Récemment elle a également été détectée dans le tissu adipeux où elle est inhibée lorsque les rats souffrent d'obésité (Guo et al 2004). La surexpression de cette protéine inhibe la différenciation, stimule la prolifération des préadipocytes et les protégerait contre l'apoptose (Zhang et al 2006). L'UCP5 (ou BMCP1) est également exprimée majoritairement dans le cerveau mais elle est exprimée également dans d'autres tissus. Elle est localisée sur le chromosome Xq24 humain (Sanchis et al 1998). L'HDMCP (HCC down regulated mitochondrial carrier protein) est une protéine mitochondriale qui est exprimée dans le foie et sous exprimée dans certains types de cancer $\mathrm{du}$ foie (HCC, hepatocellular carcino$m e$ ). Elle dissipe le potentiel de membrane et serait donc une nouvelle UCP hépatique (Tan et al 2004). La KMCP1 est une UCP identifiée très récemment et majoritairement exprimée dans le rein. Elle serait associée aux mécanismes de protection contre les EAO (Hagenauer et al 2005).

\section{e) L'UCP aviaire (avUCP)}

L'UCP aviaire (Raimbault et al 2001) clonée chez le poulet est une protéine dont la séquence est de 307 acides aminés. Elle partage respectivement 55, 70, 70 et $46 \%$ d'identité de séquence avec les homologues UCP1, UCP2, UCP3 et UCP de plantes. Des homologues de cette protéine ont également été mis en évidence chez le canard, la dinde, le manchot, le colibri et l'eider à duvet (Mozo et al 2005). Son expression a tout d'abord été détectée majoritairement dans les muscles squelettiques, mais également dans la rate, le cerveau, et dans une moindre mesure dans le cœur, le foie, les reins et le poumon (Evock-Clover et al 2002). Il semble que l'activité de cette UCP soit stimulable par l'ion superoxyde et inhibée par le GDP (Talbot et al 2004). Comme c'est le cas pour UCP1 de mammifères, l'activité découplante de l'UCP aviaire est stimulée par l'acide rétinoïque quand cette protéine est surexprimée dans la levure (Criscuolo et al 2005).

\section{4 / Un mécanisme biochimique encore controversé}

Le mécanisme biochimique des UCP est encore très controversé mais à l'image des études réalisées sur l'UCP1, deux hypothèses concurrentes ont été avancées. Ce sont les théories du canal protonique et d'un cycle futile des acides gras.

\section{a) Théorie du canal protonique}

Selon Arechaga et al (2001) et les études topologiques réalisées par Miroux et al (1993), l'UCP1 est constituée de deux domaines : un canal situé sur la face externe de la MMI qui permet aux protons de traverser la membrane et une porte située sur la face interne de la MMI qui détermine la spécificité du transport. Selon la théorie du canal protonique, proposée par Klingenberg et al en 1999, l'UCP1 prend en charge le proton grâce à un acide gras libre ionisé qui tel un groupement prosthétique favorise le passage du proton et le positionne près de résidus aminés actifs de l'UCP1 (figure 5.1). On suppose alors que ces acides aminés (l'acide glutamique ou l'acide aspartique) participent au transport grâce à l'état de protonation de la fonction carboxylique formant ou non un pont salin nécessaire au transport. La mutation de 2 histidines (His ${ }_{145}$ et His Hit7 $_{14}$ ) inactive le transport de protons catalysé par UCP1 (Bienengraeber et al 1998). Cependant, le rôle de ces histidines n'a pu être confirmé par d'autres auteurs (Jimenez-Jimenez 2006).

\footnotetext{
b) Théorie d'un cycle futile d'acides gras

Dans ce modèle soutenu par Garlid, Jezek et Skulachev (Skulachev 1991, Jezek et al 1994), l'UCP1 transporte les acides gras sous leur forme anionique
} 
Figure 5. Mécanismes biochimiques proposés pour le transport de protons par l'UCP1.

\section{1}

Espace intermembranaire

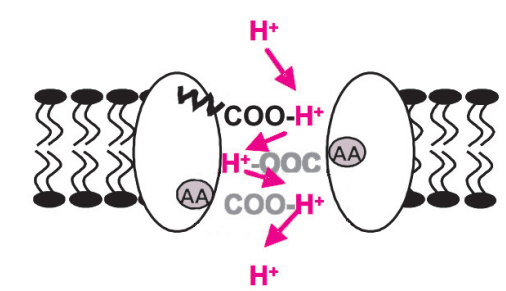

Matrice mitochondriale

$1 /$ canal protonique ; 2 / cycle futile d'acides gras

et c'est la molécule d'acide gras libre qui prend en charge le proton (lors de sa protonation) et lui permet de franchir la bicouche lipidique de la MMI (figure 5.2). Cette hypothèse est soutenue par le fait que l'UCP1 est capable de transporter des anions dont des acides gras (Jezek et Garlid 1990). En revanche, les alkylsulfonates (acides gras modifiés ne pouvant pas franchir la bicouche lipidique de la MMI) sont capables d'induire un découplage de la respiration dans les mitochondries isolées (Rial et al 2004), ce qui va à l'encontre d'un transport de protons via un cycle futile d'acides gras. Cependant, les alkylsufonates sont des acides forts et à un $\mathrm{pH}$ physiologique ils ne devraient pas se trouver sous leur forme protonée ; ce qui n'est pas non plus compatible avec la théorie du canal protonique.

\section{5 / Régulation de l'activité des protéines apparentées à l'UCP1}

A l'image d'UCP1, les UCP sont régulées à la fois au niveau de la transcription, de la traduction et au niveau de leur activité découplante. D'ailleurs, plusieurs études montrent des divergences entre l'expression de l'ARNm et le contenu protéique (Pecqueur et al 2001, Jimenez et al 2002). Les niveaux d'expression physiologiques de l'UCP2 et de 1'UCP3 sont extrêmement faibles par rapport à l'UCP1. Dans le muscle de souris, la quantité d'UCP3 est estimée à 140 ng par mg de protéines mitochondriales (Cadenas et al 2002). En comparaison, la quantité d'UCP1 dans le TAB serait comprise entre 5 et $50 \mu \mathrm{g}$ par $\mathrm{mg}$ de protéines mitochondriales (Stuart et al 2001). De ce fait l'étude de leur activité biochimique est délicate et souvent comparée à l'activité de l'UCP1. L'activité biochimique des UCP apparentées à

\section{2}

Espace intermembranaire

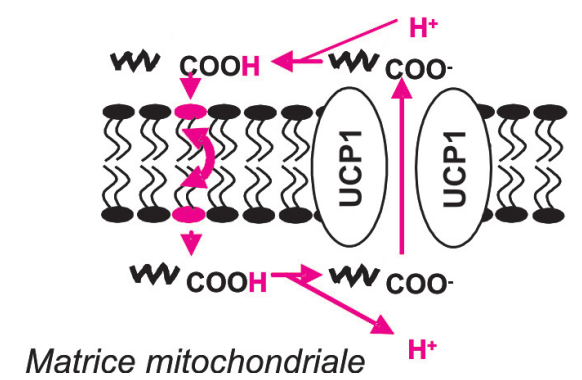

l'UCP1 est encore très controversée et il n'est pas encore certain qu'à l'image d'UCP1, elles transportent des protons (Mozo et al 2006, Couplan et al 2002).

Jaburek et al (1999) ont montré in vitro (liposomes) que l'UCP2 et 1'UCP3 possédaient une activité biochimique comparable à celle de 1'UCP1. Elles catalysent un transport de protons activé par les acides gras et inhibé par les nucléotides phosphates (Jaburek et Garlid 2003). De même, exprimées dans la levure, l'UCP2 (Fleury et al 1997) et l'UCP3 (Zhang et al 1999) induisent un découplage respiratoire partiel qui se traduit par une baisse du potentiel de membrane. Certaines études ne montrent en revanche aucune relation entre l'expression de ces protéines homologues et un découplage respiratoire (Echtay et al 1999, Stuart et al 2001, Harper et al 2002, Cadenas et al 2002, Hesselink et al 2003). Les modèles transgéniques utilisant la surexpression de ces protéines ont été beaucoup décriés car les quantités d'UCP étaient trop importantes par rapport aux niveaux physiologiques. De ce fait, la fuite de protons enregistrée serait non spécifique probablement à cause d'un mauvais repliement des protéines dans la MMI ou d'une mauvaise intégration membranaire (Guerini et al 2002). Les modèles utilisant l'ablation de gènes apparaissent alors très utiles pour tenter de lever ces contradictions car ils permettent d'étudier l'impact des UCP dans des conditions physiologiques. Cependant, Cadenas et al (2002) n'observent aucune différence de potentiel de membrane entre des souris sauvages et des souris dont le gène UCP3 est délété. D'autres études rapportent en revanche que le couplage est augmenté ou que la fuite de protons est diminuée chez les souris n'exprimant pas 1'UCP3 (Vidal-Puig et al 2000, Cline et al 2001, Gong et al 2000). Pour 1'UCP2, la situation n'est pas plus claire car l'ablation du gène UCP2 peut augmenter ou non le découplage (Couplan et al 2002, Echtay et al 2002, Krauss et al 2002). De même, les études sur la régulation par les nucléotides phosphates fournissent des résultats contradictoires. Echtay et al (1999) ont montré que l'UCP3 était plus sensible aux nucléotides diphosphates tandis que l'UCP1 était plus sensible aux nucléotides triphosphates. Dans une autre étude ces auteurs montrent que la sensibilité aux nucléotides est différente entre 1'UCP2 et 1'UCP3 (Echtay et al 2001). En revanche, Jaburek et Garlid (2003) montre que l'ATP inhibe de façon identique 1'UCP1, l'UCP2 et l'UCP3 tandis que Zackova et al (2003) propose une décroissance d'inhibition dans l'ordre suivant, ADP $>$ ATP GTP > GDP, pour 1'UCP2 et 1'UCP3. L'effet des acides gras sur l'activité de 1'UCP2 et de 1'UCP3 a été testé dans des systèmes recombinants non pertinents (cf ci-dessus) et dans des mitochondries isolées de muscle (Hirabara et al 2006). Parmi les 4 acides gras testés dans le muscle, seul l'acide linoléique est capable d'induire un découplage de type UCP (inhibition par le GDP). Ces divergences de résultats ont guidé les recherches vers d'autres régulateurs physiologiques pour ces homologues. L'anion superoxyde (Echtay et al 2002), l'hydoxynonenal (HNE) et le coenzyme Q (Jarmuszkiewicz et al 2004) seraient des activateurs indispensables de ces protéines (cf 3.4, Esteves et Brand 2005). Dans des mitochondries isolées, les UCP 2 et 3 ne transportent pas de protons tant qu'elles ne sont pas activées par le HNE (Esteves et Brand 2005, Brand et al 2004). Les acides gras sont de très modestes activateurs de ces protéines et n'ont pas d'effet sur l'activation par le HNE (Echtay et al 2003).

Enfin très récemment, Mozo et al (2006) ne montrent aucun découplage respiratoire dans la lignée cellulaire $\mathrm{CHO}$ (cellules d'ovaires de hamster) exprimant 1'UCP3 et 1'UCP1. En présence d'acide rétinoïque le découplage est restauré dans les cellules exprimant l'UCP1 tandis que ce traitement est sans effet dans les cellules exprimant l'UCP3. La variation de potentiel de membrane correspondant à la transition Etat 3 vers Etat 4 est plus forte dans les cellules contrôles que dans les cellules exprimant l'UCP3 en présence de glucose tandis qu'en présence de galactose (pas de production d'ATP par la glyco- 
lyse) cette différence est annihilée. L'UCP1 ayant la capacité de transporter le pyruvate (Jezek et Borecky 1998), Mozo et al (2006) émettent l'hypothèse qu'en l'absence d'un inducteur spécifique nécessaire au transport de protons, l'UCP3 induise un découplage en facilitant le transport passif du pyruvate de la matrice mitochondriale vers le cytosol. Le transport du pyruvate permettrait de lever l'inhibition de la glycolyse par l'ATP mitochondrial. L'UCP3 maintiendrait ici l'équilibre entre les productions d'ATP mitochondriale et cytosolique. Cette hypothèse permettrait de mieux appréhender l'expression préférentielle de 1'UCP3 dans les muscles glycolytiques où les 2 métabolismes (oxydatif et glycolytique) coexistent (Jimenez et al 2002). Enfin, cette hypothèse est compatible avec la très faible quantité de protéine présente dans le muscle (200 fois moins importante que l'UCP1 dans le $\mathrm{TAB})$, car ce transport ne semble pas dépendre de la quantité de protéine exprimée.

\section{3 / Les homologues d'UCP1 : des protéines en quête de fonctions}

La découverte de protéines apparentées (UCP 2 à 5) et l'appellation "protéines découplantes» immédiatement attribuée en raison de fortes homologies de séquence, ont eu des conséquences sur les recherches menées sur la fonction de ces nouvelles protéines. Ainsi, les investigations portant sur le rôle physiologique de ces protéines ont prioritairement porté sur leur implication dans la dissipation d'énergie et le métabolisme énergétique. Mais à l'image de Negre-Salvayre et al (1997) qui rapidement après la découverte d'UCP2, ont proposé que les UCP soient impliquées dans le contrôle de la production d'EAO, de nombreuses hypothèses sont maintenant émises sur le rôle physiologique des protéines apparentées à l'UCP1 (Brand et Esteves 2005, Krauss et al 2005, Mozo et al 2005, Nedergaard et al 2005).

\section{1 / Thermogenèse et métabo- lisme}

Chez les mammifères, la production de chaleur ou thermogenèse constitue la plus importante dépense énergétique. L'absence de TAB (donc d'UCP1) chez l'homme adulte et la découverte de nouvelles UCP exprimées dans de nombreux tissus sont à l'origine des recherches sur le rôle de ces protéines dans la thermogenèse et le contrôle de la balance énergétique. De plus, le muscle représentant $40 \%$ de la masse corporelle, il participe considérablement aux dépenses énergétiques de l'organisme. Aussi, malgré la faible expression des UCP et leur faible découplage (de l'ordre de $15 \%$ par rapport au TAB), ces protéines pourraient jouer un rôle métabolique important dans ce tissu.

Les premières études (Boss et al 1998a, Samec et al 1998) n'ont pas montré d'effet important d'une exposition au froid sur l'expression des gènes UCP2 et UCP3. De plus, l'ablation des gènes UCP2 ou UCP3 ne modifie pas la thermogenèse des souris transgéniques par rapport aux souris sauvages (Arsenijevic et al 2000, Zhang et al 2001, Vidal-Puig et al 2000). Ceci suggère que dans des conditions physiologiques normales l'UCP3 et l'UCP2 ne contrôlent pas la production de chaleur. Toutefois, une étude montre que l'hyperthermie musculaire induite par la prise de N-methyl-D-aspartate (ecstasy) est inhibée par l'ablation du gène UCP3 chez la souris et qu'il n'y a pas de phénomène d'overdose chez ces animaux (Mills et al 2003).

Chez les oiseaux, il existe à la fois une thermogenèse de frisson et une thermogenèse sans frisson (NST, Barré et al 1989), notamment au niveau du tissu musculaire. Cette thermogenèse sans frisson pourrait être relayée au niveau musculaire par un cycle futile de calcium, mais aussi par des fuites de protons au niveau de la MMI. Les études menées sur l'UCP aviaire montrent que l'expression de son messager est fortement stimulée chez le canard adapté au froid (Raimbault et al 2001) et dans une moindre mesure chez le poulet exposé quelques jours à un froid modéré (Toyomizu et al 2002, Collin et al 2003a). Cette surexpression, concomitante avec une augmentation des taux circulants de T3 et de la production de chaleur (Collin et al 2003a), ainsi que la régulation par les hormones thyroïdiennes et le glucagon qui stimulent la thermogenèse chez l'oiseau, vont dans le sens d'une implication d'avUCP dans la thermogenèse. En effet, une supplémentation alimentaire en T3 double l'expression du messager d'avUCP et l'inhibition de la glande thyroïde diminue de $75 \%$ son expression chez le poulet (Collin et al 2003c). Les manchots, naturellement adaptés au froid, présentent également une augmentation de l'expression du messager de l'UCP aviaire, mais aussi de l'ANT, lors de leur premier plongeon en eau froide (Talbot et al 2004). L'activation de ces protéines pourrait être dépendante d'une stimulation par l'ion superoxyde (Talbot et al 2004). Enfin, Vianna et al (2001) suggèrent chez le colibri une implication de l'UCP dans la phase de réchauffement suivant les phases de torpeur pendant lesquelles la température interne de cet oiseau diminue considérablement.

Ces données suggèrent que l'UCP aviaire joue un rôle dans le maintien de la température corporelle. Comme UCP1, elle pourrait ainsi participer au découplage entre oxydations et phosphorylations, dissipant l'énergie du gradient de proton pour produire de la chaleur au détriment de la synthèse d'ATP. Ces résultats restent cependant à confirmer au niveau protéique, ce qui nécessite l'utilisation d'un anticorps spécifique aux espèces aviaires.

L'implication des UCP dans le contrôle de l'efficacité métabolique n'est pas clairement établie. En effet, des situations physiologiques qui nécessitent de limiter la dissipation d'énergie (jeûne, activité physique) augmentent les taux d'ARNm de l'UCP2 comme de l'UCP3 et d'avUCP (Boss et al 1998b, Millet et al 1997, Cortright et al 1999, EvockClover et al 2002). De plus, le métabolisme basal de souris n'exprimant pas l'UCP3 est identique à celui de souris sauvages (Gong et al 2000). Enfin, Boivin et al (2000) montrent chez l'homme que la variabilité d'expression de l'UCP2 et de l'UCP3 n'est pas corrélée à la variabilité des dépenses énergétiques. Cependant, des analyses génétiques ont montré l'existence d'une liaison génétique entre le métabolisme basal et le locus UCP2-UCP3 (Bouchard et al 1997). Chez les indiens Pima, des corrélations positives ont été également détectées entre le métabolisme basal et l'expression de 1'UCP2 (Walder et al 1998) ou de l'UCP3 (Schrauwen et al 1999).

On ne peut donc pas totalement exclure les UCP de la régulation du métabolisme basal mais il semble que ce contrôle s'effectue dans certaines conditions physiologiques et que la contribution des UCP soit relativement modeste. Ce faible impact pourrait être lié au site d'expression car si on exprime l'UCP1 dans le cœur où la synthèse d'ATP est plus active (inhibition des UCP) que dans le TAB, l'efficacité 
métabolique n'est pas modifiée (Hoerter et al 2004). La découverte de nouveaux activateurs physiologiques des UCP permettrait peut-être de dénouer la situation.

Cependant, Sluse et al (2006) ont récemment proposé que l'UCP3 régule la production d'ATP en fonction des besoins de la cellule (contrôle de la balance énergétique). Cette implication est liée au statut redox du coenzyme Q (Jarmuszkiewicz et al 2004). Lorsque les besoins de la cellule en ATP sont élevés, le coenzyme $\mathrm{Q}$ serait sous sa forme oxydée, les nucléotides phosphates inhiberaient l'UCP3 au profit d'une forte synthèse d'ATP. En revanche, quand les besoins en ATP sont réduits, le coenzyme $\mathrm{Q}$ réduit serait capable, par des mécanismes encore inconnus, de lever l'inhibition de l'UCP3 par les nucléotides phosphates au détriment de la synthèse d'ATP. Cette hypothèse permet d'expliquer l'existence d'un découplage in vivo en dépit de fortes concentrations $(2-15 \mathrm{mM})$ de nucléotides phosphates. Le statut redox du coenzyme Q serait donc le signal intracellulaire contrôlant la production d'ATP (figure 6.1). Cependant, une autre étude montre que le coenzyme Q n'active pas les UCP (Jaburek et Garlid 2003).

\section{2 / Rôle d'UCP3 et d'avUCP dans le métabolisme lipidique}

Cette théorie proposée pour l'UCP3 par Himms-Hagen et Harper (2001), Schrauwen et al (2001) et Goglia et Skulachev (2003) repose sur le modèle d'un cycle futile d'acides gras et l'équilibre entre la disponibilité des acides gras et la capacité oxydative de la mitochondrie (Brand et Esteves 2005, Krauss et al 2005, Schrauwen et al 2006a). Plusieurs études montrent une corrélation positive entre l'expression d'UCP3 et l'oxydation des acides gras (Mac Lellan et al 2005, Bezaire et al 2005). Cependant, Schrauwen et al (2003) rapportent que la quantité de protéine UCP3 est augmentée lors de l'inhibition de la carnitine palmitoyl transférase 1 (CPT1, enzyme limitante de la $\beta$-oxydation). En revanche, l'UCP3 est fortement exprimée dans des situations où la quantité d'acides gras dépasse la capacité oxydative de la mitochondrie : jeûne, régime hyperlipidique, effort intense, muscle glycolytique (Millet et al 1997, Weigle et al 1998, Schrauwen et al 2002, Hesselink et al 2001). De même, l'expression de l'ARN messager d'avUCP est plus élevée chez le poulet nourri avec un régi- me à plus fort taux de lipides (8\%) comparativement à au poulet nourri avec un régime iso-énergétique mais contenant seulement $3 \%$ de lipides (Collin et al 2003b). Cependant, dans des situations ou la capacité oxydative de la mitochondrie est très importante, 1'UCP3 est faiblement exprimé : perte de poids, exercice physique d'endurance, muscle oxydatif (Vidal-Puig et al 1999, Boss et al 1998b, Hesselink et al 2001).

Dans ce modèle, l'UCP3 transporterait les anions d'acides gras de la MMI vers le cytosol afin 1) d'augmenter la capacité oxydative des mitochondries (renouvellement du Coenzyme Ax, $\mathrm{CoASH}$ ) et 2) de limiter leur peroxydation. Quand les acides gras sont en excès par rapport à la capacité oxydative de la mitochondrie, une thioestérase mitochondriale (MTE1, figure 6.2) hydrolyse l'acyl-CoA en un anion d'acide gras et du CoASH. Celui-ci active l'oxydation des acides gras car c'est un cofacteur de la $\beta$-oxydation et du cycle de Krebs. En absence d'acyl CoA synthase (ACS) dans la matrice mitochondriale, l'anion d'acide gras ne peut être oxydé dans la mitochondrie mais il est transporté au travers de la MMI par l'UCP3. Il se recondense en acyl-CoA lors de l'estérification par l'acyl CoA synthase (ACS) de la membrane mitochondriale externe. D'autre part, si les acides gras en excès traversent la MMI et se retrouvent dans la matrice mitochondriale sous forme d'anions d'acides gras (cycle futile d'acides gras) ils ne peuvent pas être oxydé, le transport par l'UCP3 permettrait d'éviter l'accumulation d'acides gras potentiellement toxiques (très sensibles à la péroxydation) dans la mitochondrie. Cette hypothèse est soutenue par le fait que la surexpression du gène UCP3 chez la souris entraîne une augmentation de l'expression du gène MTE1 (Moore et al 2001). De plus, la péroxydation lipidique est augmentée après invalidation du gène UCP3 chez la souris (Brand et al 2002).

Goglia et Skulachev (2003) proposent que les UCP (2 à 5) transportent des peroxydes d'acides gras issus de la peroxydation des phospholipides membranaires afin d'éviter les dommages cellulaires causés par ces composés. De plus, Jaburek et al (2004) montre que la forme protonée de ces peroxydes peut traverser la MMI et induire un découplage via un cycle futile d'acides gras.

Ces théories sont très critiquées en raison de la remise en question de la théorie du cycle futile d'acides gras (Brand et Esteves 2005). Toutefois, cette hypothèse est cohérente avec l'expression préférentielle d'UCP3 dans les muscles glycolytique qui oxydent faiblement les acides gras

\section{3 / Contrôle de la produc- tion d'Espèces Actives de l'Oxygène}

\section{a) La production d'EAO}

La production mitochondriale d'EAO est bien établie et contribue de façon importante au vieillissement et à l'étiologie de nombreuses pathologies. Toutes les mitochondries de tous les tissus de tous les organismes produisent des EAO au cours de la respiration mitochondriale par effet secondaire. Il existe 3 sites de production d'EAO dans la mitochondrie : le complexe 1, le complexe 3 et le coenzyme Q réduit (figure 6.3). Une force proton motrice élevée ralentit le flux d'électrons dans la chaîne respiratoire et favorise ainsi leur fuite dans la matrice où ils réagissent avec l'oxygène conduisant à la formation du radical superoxyde $\mathrm{O}_{2}{ }^{\bullet}$. Ainsi, la production d'EAO dépend de l'activité mitochondriale et elle est maximale quand la force proton motrice est maximale. La relation entre le potentiel de membrane et la production mitochondriale d'EAO est très forte. Ainsi une diminution de $10 \%$ du potentiel de membrane («découplage léger») peut diminuer la production d'EAO de 50 à $70 \%$ (Starkov 2006). En cas de pathologies, la production d'EAO peut augmenter ou diminuer sans dépendance vis-à-vis de la force proton motrice. Les mitochondries possèdent une capacité de détoxification des EAO très efficace pour les EAO exogènes mais moins performante pour les EAO endogènes qui sont produits à proximité de sites très sensibles à leur action (membrane lipidique, protéines mitochondriales, ADN mitochondrial...). De ce fait diminuer le potentiel de membrane sans affecter la capacité énergétique des mitochondries est la voie la plus prometteuse pour diminuer la production d'EAO. Ce concept de «découplage léger» (mild uncoupling, Starkov 2006) suppose qu'une faible diminution du potentiel de membrane diminue fortement la production d'EAO sans affecter la production d'énergie dans la mitochondrie. Les UCP apparentées à 1'UCP1 qui semblent découpler faiblement la respiration, pourraient ainsi réguler la production d'EAO. 
Figure 6. Rôles physiologiques des UCPs.
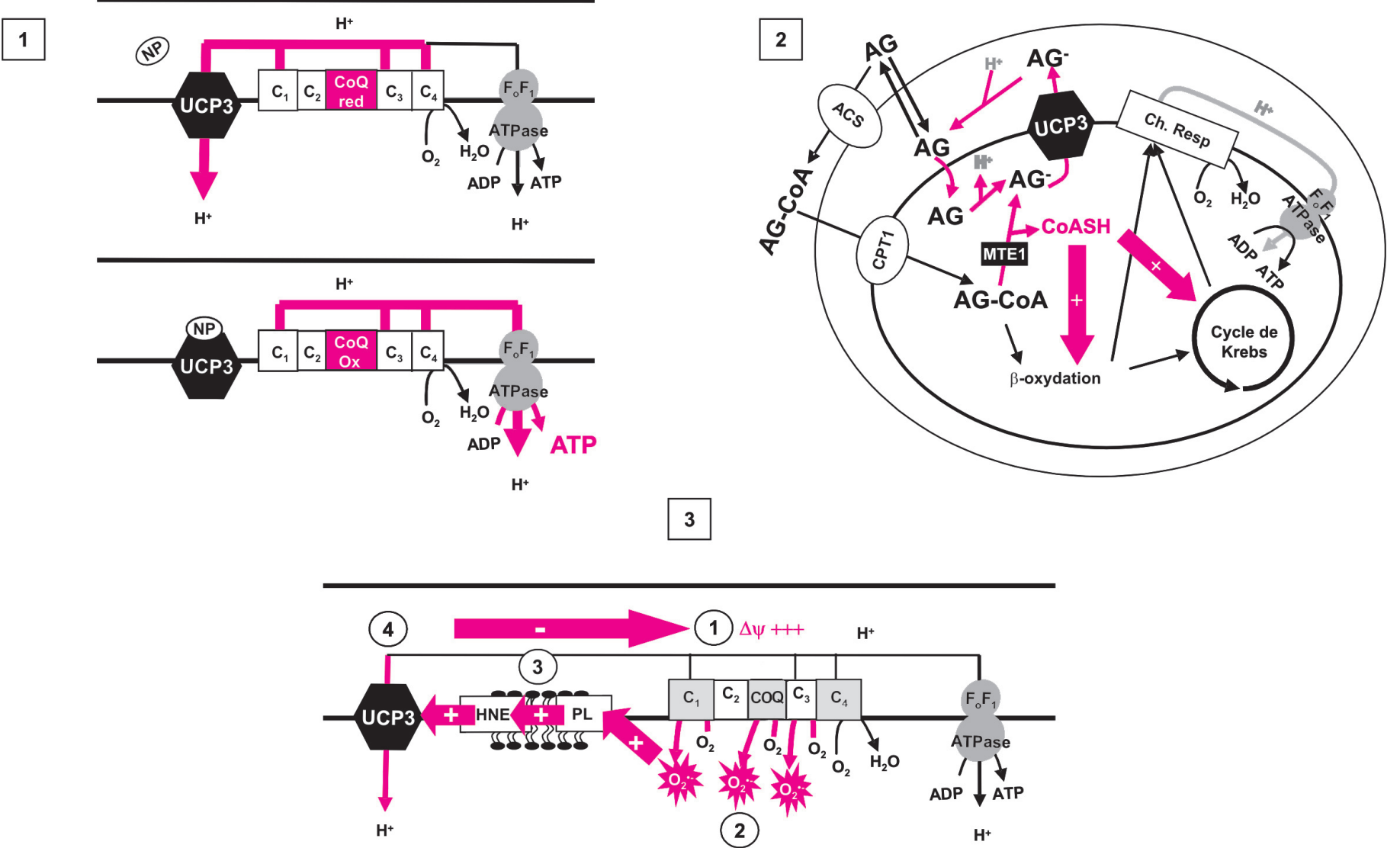

1/ Synthèse d'ATP ; 2/ Transport d'acides gras ; 3 Limitation de la production d'EAO (Espèces Actives de l'oxygène).

\section{b) Régulation de la production} d'EAO

En 1997, Negre-Salvayre et al ont été les premiers à montrer que 1'UCP2 limitait la production d'EAO. De plus, des souris dont le gène UCP2 ou UCP3 a été invalidé possèdent une production d'EAO plus importante dans leur muscle (UCP3) et dans leurs macrophages (UCP2) que les souris sauvages et présentent des dommages oxydatifs (Arsenijevic et al 2000, Vidal-Puig et al 2000). Il a alors été suggéré que le «découplage léger» qui limitait la production d'EAO était dû aux UCP. Aujourd'hui, un modèle plus détaillé de régulation a été proposé par Brand et al (2004) dans lequel les EAO activent 1'UCP2-3 qui en retour limite leur production (rétro contrôle négatif, figure 6.3). L'augmentation du niveau endogène $\mathrm{d}^{\prime} \mathrm{O}_{2}{ }^{\circ-}$ stimule la peroxydation des phospholipides membranaires qui conduit à la production d'hydoxynonenal (HNE). Ce peroxyde lipidique est un activateur de 1'UCP2-3 (Echtay et al 2005). De ce fait, on observe une diminution du potentiel de membrane («découplage léger») qui diminue la production d'EAO.
Chez l'oiseau, plusieurs arguments permettent également de suggérer une implication de l'UCP aviaire dans la limitation de la production d'EAO. Comme UCP2, cette protéine est exprimée dans des tissus participant à la défense immunitaire comme la rate ou les poumons (Evock-Clover et al 2002). De plus, Talbot et al (2003, 2004) suggèrent que l'activité de l'UCP aviaire est stimulée par l'ion superoxyde chez le jeune manchot. Criscuolo et al (2005) montrent par ailleurs qu'une surexpression d'avUCP dans la levure réduit les dommages oxydatifs cellulaires liés aux radicaux libres. Ce mécanisme pourrait permet-tre de limiter les dommages oxydatifs dans des espèces caractérisées par un métabolisme basal élevé et une forte glycémie. Il est à l'heure actuelle difficile de savoir si l'UCP aviaire intervient à la fois dans les mécanismes de thermogenèse et de régulation de la production de radicaux libres puisque les mécanismes mis en jeu pour favoriser la thermogenèse sont souvent générateurs d'oxydations cellulaires.

\section{4 / Implications physiopa- thologiques}

En dépit d'une fonction clairement établie, plusieurs études ont montré que les UCP pourraient être associées à de nombreuses pathologies (Nubel et Ricquier 2006).

\section{1 / Le vieillissement et la durée de vie}

Chez tous les organismes, les dommages tissulaires augmentent avec l'âge sous l'effet d'une accumulation d'EAO générés par la mitochondrie (Harman 1956) : théorie radicalaire du vieillissement. Récemment, Speakman et al (2004) ont mis en évidence sur des cohortes de souris, une corrélation positive entre leur durée de vie et la consommation énergétique de l'animal entier. Les mitochondries des souris possédant le métabolisme le plus actif, sont plus découplées (plus d'ANT et UCP3) ce qui les prédisposeraient à une longévité plus importante.

Barazzoni et Nair (2001) ont également montré que l'expression des 
gènes UCP2 et UCP3 dans le muscle, le foie et le cœur pouvait être modifiée au cours du vieillissement. Ainsi, Kerner et al (2001) montrent que des rats âgés possèdent moins d'UCP3 que des jeunes ratons et suggèrent qu'une production accrue d'EAO pourrait induire des dommages mitochondriaux et expliquer la diminution des capacités oxydatives lors du vieillissement. Cependant, aucune n'étude ne rapporte de modification de la durée de vie des souris n'exprimant pas ces UCP. Enfin, dans une synthèse récente, Wolkow et Iser (2006) rapporte que les données dans ce domaine sont peu nombreuses et très contradictoires.

\section{2 / L'inflammation et l'athé- rosclérose}

L'athérosclérose est une maladie inflammatoire chronique des artères qui se caractérisent par une accumulation de lipides, de cellules inflammatoires et de matrice extracellulaire dans l'artère. La première étape dans la mise en place de cette inflammation est l'oxydation de lipoprotéines de faibles densités (LDL) qui entrainent la formation d'une plaque d'athérome dans la paroi artérielle. Cette plaque peut se développer sous l'action des EAO. Le rôle des EAO dans la formation et l'évolution de la plaque d'athérome et l'activation des UCP par ces composés suggèrent l'implication des UCP dans le développement de cette pathologie. De plus, l'UCP2 est induite par des agents inflammatoires comme les lipopolysaccharides (Pecqueur et al 2001) et l'invalidation du gène UCP2 chez la souris augmente la résistance à l'infection par un parasite intracellulaire (Toxoplasma gondii ) car ces souris produisent plus d'EAO (Arsenijevic et al 2000). La transplantation de moelle osseuse de souris invalidées pour l'UCP2 dans des cellules irradiées de souris déficientes en récepteur au LDL augmente la taille des plaques d'athérome et la production d'EAO (Blanc et al 2003). Ces auteurs proposent alors que l'UCP2 joue un rôle protecteur dans l'athérosclérose. Une étude sur le polymorphisme du gène UCP2 confirme ces résultats (Oberkofler et al 2005).

Le stress oxydant et l'inflammation sont impliqués dans diverses pathologies neurodégénératives comme la sclérose en plaque ou la maladie de
Parkinson. L'UCP2 pourrait également contrôler l'inflammation des fibres nerveuses observée dans la sclérose en plaque. En effet, le niveau d'expression d'UCP2 est diminué chez des sujets atteints de cette maladie. Une augmentation de la production d'EAO pourrait être à l'origine de l'augmentation des phénomènes inflammatoires (Vogler et al 2005). De plus, des souris invalidées pour le gène UCP2 développent une inflammation plus sévère que les souris sauvages (Vogler et al 2006). D'autre part, des expériences conduites sur des souris invalidées pour l'UCP2 montrent que ce gène pourrait limiter le déclin des neurones produisant de la dopamine observé dans la maladie de Parkinson (Andrews et al 2005).

\section{3 / Le diabète non insulinodé- pendant et la lipotoxicité}

Récemment, Schrauwen et al (2006b) montrent que la quantité d'UCP3 est diminuée (40\%) chez des diabétiques. Ils suggèrent que l'UCP3 puisse intervenir dans les processus d'insulinorésistance car l'expression d'UCP3 est positivement corrélée avec le taux de lipides intramusculaires et une diminution du métabolisme oxydatif. Le traitement par un antidiabétique (rosiglitazone) augmente l'expression d'UCP3 et améliore la sensibilité à l'insuline. Chez les diabétiques, une disponibilité en acides gras importante et des capacités oxydatives réduites devraient conduire à une induction de 1'UCP3 (cf 3.2). La situation inverse est observée et cette diminution d'UCP3 pourrait être à l'origine de cette pathologie en augmentant la peroxydation lipidique et la production d'EAO. Une autre étude conforte ce résultat en mettant en évidence d'importants dommages oxydatifs chez des souris invalidées pour l'UCP. Cependant, ces souris ne deviennent pas diabétiques !

L'UCP2 pourrait également être impliquée dans le développement du diabète car elle inhibe la sécrétion d'insuline (Krauss et al 2005). En effet, la sécrétion d'insuline est plus importante chez des souris n'exprimant pas l'UCP2 par rapport aux souris sauvages (Zhang et al 2001). Chez les souris sauvages la sécrétion d'insuline dépend du rapport ATP/ADP. L'ATP active la fer- meture d'un canal potassique, créant une dépolarisation qui permet l'entrée du calcium dans la cellule $\beta$-pancréatique qui stimule la sécrétion d'insuline. L'UCP2 inhiberait la fermeture du canal potassique en diminuant la synthèse d'ATP.

\section{4 / L'obésité}

Dans ce domaine encore les résultats obtenus sont contradictoires. Les souris dont le gène UCP2 ou UCP3 a été délété ne deviennent pas obèses même si elles ingèrent un régime hyperlipidique (Gong et al 2000, Vidal-Puig et al 2000, Arsenijevic et al 2000). En revanche, une réduction de l'expression d'UCP2 est observée chez les obèses (Oberkofler et al 1998). Cependant, Clapham et al (2000) rapportent que des souris n'exprimant pas l'UCP3 sont hyperphagiques mais maigres. Il est difficile à l'heure actuelle d'établir un lien entre les polymorphismes des gènes UCP2 et UCP3 et l'obésité. Récemment une étude rapporte qu'un polymorphisme du gène UCP2 (-866G/A) est associé à une adiposité accrue et un risque de syndrome métabolique dans une population d'hommes asiatiques (Shen et al 2006). Cependant, dans une synthèse sur le rôle des UCP dans l'obésité, Dalgaard et Pedersen (2001) montre que lorsque les effets des polymorphismes sur l'obésité sont avérés, ils sont relativement modestes.

\section{Conclusion}

Il est actuellement bien admis que les UCP participent au découplage de la respiration mitochondriale. Cependant, les recherches déjà très actives dans ce domaine doivent être poursuivies. L'étude des mécanismes biochimiques de ce découplage grâce à la mise en évidence de nouveaux régulateurs et l'analyse de la structure tridimensionnelle permettront peut être de lever le voile sur le rôle physiologique de ces protéines. En effet, une meilleure compréhension de la fonction et de la régulation de ces protéines est une perspective très attrayante au regard de leur implication dans un certain nombre de pathologies : diabète, obésité, maladies inflammatoires... 


\section{Références}

Acin A., Rodriguez M., Rique H., Canet E., Boutin J.A., Galizzi J.P., 1999. Cloning and characterization of the 5 , flanking region of the human uncoupling protein 3 (UCP3) gene. Biochem. Biophys. Res. Commun., 258, 278283.

Andrews Z.B., Horvath B., Barnstable C.J., Elsworth J., Yang L., Beal M.F., Roth R.H., Matthews R.T., Horvath T.L., 2005. Uncoupling protein-2 is critical for nigral dopamine cell survival in a mouse model of Parkinson's disease. J. Neurosci., 25, 184-191.

Aquila H., Link T.A., Klingenberg M., 1985. The uncoupling protein from brown fat mitochondria is related to the mitochondrial ADP/ATP carrier. Analysis of sequencies homologies and of folding of the protein in the membrane. EMBO J., 4, 2369-2376.

Arco A.D., Satrustegui J., 2005. New mitochondrial carriers, an overview. Cell Mol. Life Sci., 62, 2204-2227.

Arechaga I., Ledesma A., Rial E., 2001. The mitochondrial uncoupling protein UCP1, a gated pore. IUBMB Life, 52, 165-173.

Arsenijevic D., Onuma H., Pecqueur C., Raimbault S., Manning B.S., Miroux B., Couplan E., Alves-Guerra MC., Goubern M., Surwit R., Bouillaud F., Richard D., Collins S., Ricquier D., 2000. Disruption of the uncoupling protein-2 gene in mice reveals a role in immunity and reactive oxygen species production. Nat. Genet., 26, 435-439.

Azzone G.F., Zoratti M., Petronilli V., Pietrobon D., 1985. The Stoichiometry of $\mathrm{H}+$ pumping in cytochrome c oxidase and the mechanism of uncoupling. J. Inorg. Biochem., $23,349-356$.

Barbera MJ., Schluter A., Pedraza N., Iglesias R., Villarroya F., Giralt M., 2001. Peroxisome proliferator activated receptor alpha activates transcription of the brown fat uncoupling protein 1 gene. A link between regulation of thermogenic and lipid oxidation patways in the brown fat cell. J. Biol. Chem., 276, 1486-1493.

Barazzoni R., Nair K.S., 2001. Changes in uncoupling protein-2 and -3 expression in aging rat skeletal muscle, liver, and heart. Am. J. Physiol. Endocrinol. Metab., 280, E413-E419.

Barré H., Duchamp C., Rouanet J.L., Dittmar A., Delhomme G., 1989. Muscular nonshivering thermogenesis in cold-acclimated ducklings. In: Physiology of cold adaptation in birds. C. Bech and R.E. Reinertsen (Eds), Plenum, New York, USA, 49-58.

Bezaire V., Spriet LL., Campbell S., Sabet N., Gerrits M., Bonen A., Harper M.E., 2005.. Constitutive UCP3 overexpression at physiological levels increases mouse skeletal muscle capacity for fatty acid transport and oxidations. FASEB J., 19, 977-979.

Bienengraeber M., Echtay K.S., Klingenberg M., 1998. H+ transport by uncoupling protein UCP1 is dependent on a histidine pair, absent in UCP-2 and UCP-3. Biochemistry, 37, 3-8.

Blanc J., Alves-Guerra M.C., Esposito B., Rousset S., Gourdy P., Ricquier D., Tedgui A., Miroux B., Mallat Z., 2003. Protective role of uncoupling protein 2 in atherosclerosis. Circulation, 107, 388-390.

Boivin M., Camirand A., Carli F., Hoffer L.J., Silva J.E., 2000. Uncoupling protein-2 and -3 messenger ribonucleic acids in adipose tissue and skeletal muscle of healthy males, variability, factors affecting expression, and relation to measures of metabolic rate. J. Clin. Endocrinol. Metab., 85, 1975-1983.

Bouchard C., Perusse L., Chagnon Y.C., Warden C., Ricquier D., 1997. Linkage between markers in the vicinity of the uncoupling protein 2 gene and resting metabolic rate in humans. Hum. Mol. Genet., 6, 1887-1889.

Bouillaud F., Ricquier D., Thibault J., Weissenbach J., 1985. Molecular approach to thermogenesis in brown adipose tissue : cDNA cloning of the mitochondrial uncoupling protein. Proc. Natl. Acad. Sci. USA, 82, 445-448.

Bouillaud F., Weissenbach J., Ricquier D. 1986. Complete cDNA derived amino acid sequence of rat brown fat uncoupling. J. Biol. Chem., 261, 1487-1490.

Boss O., Samec S., Paoloni-Giacobino A. 1997. Uncoupling protein 3, a new member of the mitochondrial carrier family with tissue-specific expression. FEBS Lett., 408, 39-42.

Boss O., Samec S., Kuhne F., Bijlenga P., Assimacopoulos-Jeannet F., Seydoux J., Giacobino JP., Muzzin P., 1998a. Uncoupling protein-3 expression in rodent skeletal muscle is modulated by food intake but not by changes in environmental temperature. J. Biol. Chem., 273, $5-8$.

Boss O., Samec S., Desplanches D., Mayet M.H., Seydoux J., Muzzin P., Giacobino J.P., 1998b. Effect of endurance training on mRNA expression of uncoupling proteins 1,2 , and 3 in the rat. FASEB J., 12, 335-339

Boss O., Hagen T., Lowell B.B., 2000. Uncoupling proteins 2 and 3, potential regulators of mitochondrial energy metabolism. Diabetes, 49, 143-156

Boyer B.B., Kozak L.P., 1991. The mitochondrial uncoupling protein gene in brown fat: correlation between DNase I hypersensitivity and expression in transgenic mice. Mol. Cell. Biol., $11,4147-4156$.

Brand M.D., 2005. The efficiency and plasticity of mitochondrial energy transduction. Biochem. Soc. Trans., 33, 897-904.

Brand M.D., Esteves T.C., 2005. Physiological functions of the mitochondrial uncoupling proteins UCP2 and UCP3. Cell Metab., 2, 85-93.

Brand M.D., Brindle K.M., Buckingham J.A., Harper J.A., Rolfe D.F.S., Stuart J.A., 1999. The significance and mechanism of mitochondrial proton conductance. Int. J. Obes., 23, S4-S11.

Brand M.D., Pamplona R., Portero-Otin M., Requena J.R., Roebuck S.J., Buckingham J.A., Clapham J.C., Cadenas S., 2002. Oxidative damage and phospholipid fatty acyl composition in skeletal muscle mitochondria from mice underexpressing or overexpressing uncoupling protein 3. Biochem. J., 368, 597-603.

Brand M.D., Affourtit C., Esteves T.C., Green K., Lambert A.J., Miwa S., Pakay J.L., Parker N., 2004. Mitochondrial superoxide, production, biological effects, and activation of uncoupling proteins. Free Radic. Biol. Med., 37, 755-767.

Brand M.D., Pakay J.L., Ocloo A., Kokoszka J., Wallace D.C., Brookes P.S., Cornwall E.J., 2005. The basal proton conductance of mito- chondria depends on adenine nucleotide translocase content. Biochem. J., 392, 353-362.

Breen E.P., Gouin S.G., Murphy A.F., Haines L.R., Jackson A.M., Pearson T.W., Murphy P.V., Porter R.K, 2006. On the mitochondrial uncoupling protein 1 function. J. Biol. Chem., 281, 2114-2119.

Brookes P.S., Hulbert A.J., Brand M.D., 1997. The proton permeability of liposomes made from mitochondrial inner membrane phospholipids: no effect of fatty acid composition. Biochim. Biophys. Acta, 1330, 157-164.

Brustovetsky N.N., Dedukhova V.I., Egorova M.V., Mokhova E.N., Skulachev V.P., 1990. Inhibitors of the ATP/ADP antiporter suppress stimulation of mitochondrial respiration and $\mathrm{H}+$ permeability by palmitate and anionic detergents. FEBS Lett., 272, 187-189.

Cadenas S., Echtay KS., Harper JA. Jekabsons MB., Buckingham JA., Grau E. Abuin A., Chapman H., Clapham JC., Brand M.D., 2002. The basal proton conductance of skeletal muscle mitochondria from transgenic mice overexpressing or lacking uncoupling protein 3. J. Biol. Chem., 277, 2773-2778.

Carroll A.M., Haines L.R., Pearson T.W. Fallon P.G., Walsh C.M., Brennan C.M., Breen E.P., Porter R.K., 2005. Identification of a functioning mitochondrial uncoupling protein 1 in thymus. J. Biol. Chem., 280, 15534-15543

Cassard-Doulcier A.M., Larose M., Matamala J.C., Champigny O., Bouillaud F., Ricquier D. 1994. In vitro interactions between nuclear proteins and uncoupling protein gene promoter reveal several putative transactivating factor including Ets1, retinoid $\mathrm{X}$ receptor, thyroid hormone receptor, and a CACCC box binding protein. J. Biol. Chem., 269, 24335-24342.

Clapham J.C., Arch J.R., Chapman H., Haynes A., Lister C., Moore G.B., Piercy V., Carter S.A., Lehner I., Smith S.A., Beeley L.J., Godden R.J., Herrity N., Skehel M., Changani K.K., Hockings P.D., Reid D.G., Squires S.M., Hatcher J., Trail B., Latcham J., Rastan S., Harper A.J., Cadenas S., Buckingham J.A., Brand M.D., Abuin A., 2000. Mice overexpressing human uncoupling protein-3 in skeletal muscle are hyperphagic and lean. Nature, 406, 415-418.

Cline G.W., Vidal-Puig A.J., Dufour S., Cadman K.S., Lowell B.B., Shulman G.I., 2001. In vivo effects of uncoupling protein 3 gene disruption on mitochondrial energy metabolism. J. Biol. Chem., 276, 20240-20244.

Collin A., Buyse J., Van As P., Darras V.M., Malheiros R.D., Moraes V.M.B., Reyns G.E. Taouis M., Decuypere E., 2003a. Cold-induced enhancement of avian uncoupling protein expression, heat production, and triiodothyronine concentrations in broiler chicks. Gen. Comp. Endocrinol., 1301, 70-77.

Collin A., Malheiros R.D., Moraes V.M.B., Van As P., Darras V.M., Taouis M., Decuypere E., Buyse J., 2003b. Effects of dietary macronutrient content on energy metabolism and uncoupling protein mRNA expression in broiler chickens. Br. J. Nutr., 902, 261-269.

Collin A., Taouis M., Buyse J., Ifuta N.B., Darras V.M., Van As P., Malheiros R.D., Moraes V.M., Decuypere E., 2003c. Thyroid status, but not insulin status, affects expression of avian uncoupling protein mRNA in chicken. 
Am. J. Physiol. Endocrinol. Metab., 2844, E771E777.

Cortright R.N., Zheng D., Jones J.P., Fluckey J.D., DiCarlo S.E., Grujic D., Lowell B.B., Dohm GL., 1999. Regulation of skeletal muscle UCP-2 and UCP-3 gene expression by exercise and denervation. Am. J. Physiol., 276, E217-E221.

Couplan E., Gonzales-Barroso M., AlvezGuerra M.C., Ricquier D., Goubern M., Bouillaud F., 2002. No evidence for a basal, retinoic or superoxide induced uncoupling activity of the uncoupling protein 2 present in spleen or lung mitochondria. J. Biol. Chem., 277, 2626826275 .

Criscuolo F., Gonzalez-Barroso M., Le Maho Y., Ricquier D., Bouillaud F., 2005. Avian uncoupling protein expressed in yeast mitochondria prevents endogenous free radical damage. Proc. Biol. Sci., 272, 803-810.

Dalgaard L.T., Pedersen O., 2001. Uncoupling proteins, functional characteristics and role in the pathogenesis of obesity and Type II diabetes. Diabetologia, 44, 946-965.

Echtay K.S., Liu Q., Caskey T., Winkler E., Frischmuth K., Bienengräber M., Klingenberg M., 1999. Regulation of UCP3 by nucleotides is different from regulation of UCP1. FEBS Lett., $450,8-12$.

Echtay K.S., Winkler E., Klingenberg M., 2000. Coenzyme Q is an obligatory cofactor for uncoupling protein function. Nature, 408, 609613.

Echtay K.S., Winkler E., Frischmuth K., Klingenberg M., 2001. Uncoupling proteins 2 and 3 are highly active $\mathrm{H}(+)$ transporters and highly nucleotide sensitive when activated by coenzyme Q (ubiquinone). Proc. Natl. Acad. Sci. USA, 98, 1416-1421.

Echtay K.S., Roussel D., St-Pierre J., Jekabsons M.B., Cadenas S., Stuart J.A., Harper J.A., Roebuck S.J., Morrison A., Pickering S., Clapham J.C., Brand M.D., 2002. Superoxide activates mitochondrial uncoupling proteins. Nature, 415, 96-99.

Echtay K.S., Esteves T.C., Pakay J.L., Jekabsons M.B., Lambert A.J., Portero-Otin M., Pamplona R., Vidal-Puig A.J., Wang S., Roebuck S.J., Brand M.D., 2003. A signalling role for 4-hydroxy-2-nonenal in regulation of mitochondrial uncoupling. EMBO J., 22, 4103-4110.

Echtay K.S., Pakay J.L., Esteves T.C., Brand M.D., 2005. Hydroxynonenal and uncoupling proteins, a model for protection against oxidative damage. Biofactors, 24, 119-130.

Enerback S., Jacobsson A., Simpson E.M., Guerra C., Yamashita H., Harper M.E., Kozak LP., 1997. Mice lacking mitochondrial uncoupling protein are cold-sensitive but not obese. Nature, 387, 90-94.

Esteves T.C., Brand M.D., 2005. The reactions catalysed by the mitochondrial uncoupling proteins UCP2 and UCP3. Biochim. Biophys. Acta, $1709,35-44$

Evock-Clover C.M., Poch S.M., Richards M.P., Ashwell C.M., McMurtry J.P., 2002. Expression of an uncoupling protein gene homolog in chickens. Comp. Biochem. Physiol. A Mol. Integr. Physiol., 1332, 345-358.

Fleury C., Neverosa M., Collin S., Raimbaut S., Champigny O., Levi-Meyrueis C., Bouillaud F., Seldin M.F., Surwitt R.S., Ricquier D., Warden C.H., 1997.. Uncoupling protein 2: a novel gene linked to obesity and hyperinsulinemia. Nat. Genet., 15, 269-272.
Goglia F., Skulachev V.P., 2003. A function for novel uncoupling proteins: antioxidant defense of mitochondrial matrix by translocating fatty acid peroxides from the inner to the outer membrane leaflet. FASEB J., 17, 1585-1591.

Gong D.W., Monemdjou S., Gavrilova O., Leon L.R., Marcus-Samuel B., Chou C.J., Everett C., Kozak L.P., Li C., Deng C., Harper M.E., Reitman M.L., 2000. Lack of obesity and normal response to fasting and thyroid hormone in mice lacking uncoupling protein 3. J. Biol. Chem., 275 16251-16257.

Guerini D., Prati E., Desai U., Nick P., Flammer R., Grüninger S., Cumin F., Kaleko M., Connelly S., Chiesi M., 2002. Uncoupling of protein 3 induces an uncontrolled uncoupling of mitochondria after expression in muscle derived L6 cells. Eur. J. Biochem., 269, 1373-1381.

Guo X.R., Gong H.X., Fei L., Ni Y.H., Chen R.H., 2004. Study on relationship between expression of UCP4 gene in rat adipose tissue and obesity. Chin. J. Child Health Care, 12, 5860

Haguenauer A., Raimbault S., Masscheleyn S., Gonzalez-barroso M.M., Criscuolo F., Plamondon J., Miroux B., Ricquier D., Richard D., Bouillaud F., Pecqueur C., 2005. A new renal mitochondrial carrier, KMCP1, is upregulated during tubular cell regeneration and induction od antioxidant enzymes. J. Biol. Chem., 280 , 22036-22043.

Hanak P., Jezek, P., 2001. Mitochondrial uncoupling proteins and phylogenesis: UCP4 as the ancestral uncoupling protein. FEBS Lett., 495, 137-141.

Harman, D., 1956. Aging: a theory based on free radical and radiation chemistry, J. Gerontol., 11, 298-300

Harper J.A., Stuart J.A., Jekabsons M.B., Roussel D., Brindle K.M., Dickinson K., Jones R.B., Brand M.D., 2002. Artifactual uncoupling by uncoupling protein 3 in yeast mitochondria at the concentrations found in mouse and rat skeletal-muscle mitochondria. Biochem. J., 361, 4956.

Hesselink M.K., Keizer H.A., Borghouts L.B., Schaart G., Kornips C.F., Slieker L.J., Sloop K.W., Saris W.H., Schrauwen P., 2001. Protein expression of UCP3 differs between human type 1 , type $2 \mathrm{a}$, and type $2 \mathrm{~b}$ fibers. FASEB J., 15 , 1071-1073.

Hesselink M.K., Greenhaff P.L., ConstantinTeodosiu D., Hultman E., Saris W.H., Nieuwlaat R. Schaart G., Kornips E., Schrauwen P., 2003. Increased uncoupling protein 3 content does not affect mitochondrial function in human skeletal muscle in vivo. J. Clin. Invest., 111, 479-486.

Himms-Hagen J., Harper M.E., 2001. Physiological role of UCP3 may be export of fatty acids from mitochondria when fatty acid oxidation predominates: an hypothesis. Exp. Biol. Med., 226, 78-84.

Hirabara S.M., Silveira L.R., Alberici L.C., Leandro C.V., Lambertucci R.H., Polimeno G.C., Cury Boaventura M.F., Procopio J., Vercesi A.E., Curi R., 2006. Acute effect of fatty acids on metabolism and mitochondrial coupling in skeletal muscle. Biochim. Biophys. Acta, 1757, 57 66

Ho P.W., Chan D.Y., Kwok K.H., Chu A.C., Ho J.W., Kung M.H., Ramsden D.B., Ho S.L., 2005. Methyl 4 phelylpyridinium ion modulates expression of mitochondrial uncoupling proteins 2,4 and 5 in catecholaminergic SK-N-SH cells. J. Neuro. Res., 81, 261-268.
Hoerter J., Gonzalez-Barroso M.D., Couplan E., Mateo P., Gelly C., Cassard-Doulcier A.M. Diolez P., Bouillaud F., 2004. Mitochondrial uncoupling protein 1 expressed in the heart of transgenic mice protects against ischemic-reperfusion damage. Circulation, 110, 528-533.

Jaburek M., Garlid K.D., 2003. Reconstitution of recombinant uncoupling proteins: UCP1, -2, and -3 have similar affinities for ATP and are unaffected by coenzyme Q10. J. Biol. Chem., 278, 25825-25831.

Jaburek M., Varecha M., Gimeno R.E. Dembski M., Jezek P., Zhang M., Burn P. Tartaglia L.A., Garlid K.D., 1999. Transport function and regulation of mitochondrial uncoupling proteins 2 and 3. J. Biol. Chem., 274, 26003-26007.

Jaburek M., Miyamoto S., Di Mascio P. Garlid K.D., Jezek P., 2004. Hydroperoxy fatty acid cycling mediated by mitochondrial uncoupling protein UCP2. J. Biol. Chem., 279, $53097-$ 53102.

Jarmuszkiewicz W., Navet R., Alberici L.C., Douette P., Sluse-Goffart C.M., Sluse F.E., Vercesi A., 2004. Redox state of endogenous coenzyme Q modulates the inhibition of linoleic acid-induced uncoupling by guanosine triphosphate in isolated skeletal muscle mitochondria. J. Bioenerg. Biomembr., 36, 493-502.

Jezek P., Garlid K.D., 1990. New substrates and competitive inhibitors of the $\mathrm{Cl}^{-}$translocating pathway of the uncoupling protein of brown adipose tissue mitochondria. J. Biol. Chem., 265, 19303-19311.

Jezek P., Borecky J., 1998. Mitochondrial uncoupling protein may participate in futile cycling of pyruvate and other monocarboxylates. Am. J. Physiol. Cell Physiol., 275, 496-504.

Jezek P., Orosz D.E., Modriansky M., Garlid K.D., 1994. Transport of anions and protons by the mitochondrial uncoupling protein and its regulation by nucleotides and fatty acids. New look at old hypotheses. J. Biol. Chem., 269, 26184-26190.

Jimenez M., Yvon C., Lehr L., Leger B., Keller P., Russell A., Kuhne F., Flandin P., Giacobino J.P., Muzzin P., 2002. Expression of uncoupling protein-3 in subsarcolemmal and intermyofibrillar mitochondria of various mouse muscle types and its modulation by fasting. Eur. J. Biochem., 269, 2878-2884

Jimenez-Jimenez J., Zardoya R., Ledesma A., Garcia de Lacoba M., Zaragoza P., Mar Gonzalez-Barroso M., Rial E., 2006. Evolutionarily distinct residues in the uncoupling protein UCP1 are essential for its characteristic basal proton conductance. J. Mol. Biol., sous presse.

Kadenbach B., 2003. Intrinsic and extrinsic uncoupling of oxidative phosphorylation. Biochim. Biophys. Acta, 1604, 77-94.

Kerner J., Turkaly P.J., Minkler P.E., Hoppel C.L., 2001. Aging skeletal muscle mitochondria in the rat: decreased uncoupling protein-3 content. Am. J. Physiol. Endocrinol. Metab., 281, E1054-E1062.

Klingenberg M., Echtay K.S., Bienengraeber M., Winkler E., Huang S.G., 1999. Structurefunction relationship in UCP1. Int. J. Obes. Relat. Metab. Disord., 23, S24-S29.

Krauss S., Zhang C.Y., Lowell B.B., 2002. A significant portion of mitochondrial protonleak in intact thymocytes depends on expression of UCP2. Proc. Natl. Acad. Sci. USA, 99, 118-122. 
Krauss S., Zhang C.Y., Lowell B.B., 2005. The mitochondrial uncoupling-protein homologues. Nat. Rev. Mol. Cell Biol., 6, 248-261.

Lanni A., Moreno M., Lombardi A., Goglia F., 2003. Thyroid hormone and uncoupling proteins. FEBS Lett., 543, 5-10.

Ledesma A., de Lacoba M.G., Rial E., 2002. The mitochondrial uncoupling proteins. Genome Biol., 3, 3015.1-3015.9.

Lin C.S., Klingenberg M., 1980. Isolation of the uncoupling protein from brown adipose tissue mitochondria. FEBS Lett., 113, 299-303.

Lombardi A., Damon M., Vincent A., Goglia F., Herpin P., 2000. Characterisation of oxidative phosphorylation in skeletal muscle mitochondria subpopulations in pig, a study using top-down elasticity analysis. FEBS Lett., 475, 84-88.

Mao W., Yu X.X., Zhong A., Li W., Brush J., Sherwood S.W., Adam S.H., Pan G., 1999. UCP4, a novel brain-specific mitochondrial protein that reduces membrane potential in mammalian cells. FEBS Lett., 443, 326-330.

MacLellan J.D., Gerrits M.F., Gowing A., Smith P.J., Wheeler M.B., Harper M.E., 2005. Physiological increases in uncoupling protein 3 augment fatty acid oxidation and decrease reactive oxygen species production without uncoupling respiration in muscle cells. Diabetes, 54, 2343-50.

McLaughlin S.G., Dilger J.P. 1980. Transport of protons across membranes by weak acids. Physiol. Rev., 60, 825-863.

Millet L., Vidal H., Andreelli F., Larrouy D., Riou J.P., Ricquier D., Laville M., Langin D., 1997. Increased uncoupling protein-2 and -3 mRNA expression during fasting in obese and lean humans. J. Clin. Invest., 100, 2665-2670.

Mills E.M., Banks M.L., Sprague J.E., Finkel T., 2003. Pharmacology: uncoupling the agony from ecstasy. Nature, 426, 403-404.

Miroux B., Frossard V., Raimbault S., Ricquier D., Bouillaud F., 1993. The topology of the brown adipose tissue mitochondrial uncoupling protein determined with antibodies against its antigenic sites revealed by a library of fusion proteins. EMBO J., 12, 3739-45.

Mitchell P., 1966. Chemiosmotic coupling in oxidative and photosynthetic phosphorylation. Biol. Rev. Camb. Philos. Soc., 41, 445-502.

Moore G.B., Himms-Hagen J., Harper M.E., Clapham J.C., 2001. Overexpression of UCP-3 in skeletal muscle of mice results in increased expression of mitochondrial thioesterase mRNA. Biochem. Biophys. Res. Commun., 283, 785790.

Mozo J., Emre Y., Bouillaud F., Ricquier D., Criscuolo F., 2005. Thermoregulation: what role for UCP in mammals and birds? Biosci. Rep., $25,227-249$.

Mozo J., Ferry G., Studeny A., Pecqueur C., Rodriguez M., Boutin J.A., Bouillaud F., 2006. Expression of UCP3 in $\mathrm{CHO}$ cells does not cause uncoupling, but controls mitochondrial activity in the presence of glucose. Biochem. J., 393, 431-439.

Nedergaard J., Ricquier D., Kozak L.P., 2005. Uncoupling proteins, current status and therapeutic prospects. EMBO Rep., 6, 917-921.

Negre-Salvayre A., Hirtz C., Carrera G., Cazenave R., Troly M., Salvayre R., Penicaud L., Casteilla L., 1997. A role for uncoupling protein-2 as a regulator of mitochondrial hydrogen peroxide generation. FASEB J., 11, 809-815.
Nibbelink M., Arnaud E., Pénicaud L., Casteilla L., 2002. La protéine découplante du tissu adipeux brun UCP1 : la fin des dogmes. Médecine/Sciences, 18, 780-783.

Nicholls D.G., 1974. Hamster brown adipose tissue mitochondria. The control of respiration and the proton electrochemical potential gradient by possible physiological effectors of the proton conductance of the inner membrane. Eur. J. Biochem., 49, 573-583.

Nicholls D.G., 2006. The physiological regulation of uncoupling proteins. Biochim. Biophys. Acta (sous presse).

Nicholls D.G., Locke R.M., 1984. Thermogenic mechanisms in brown fat. Physiol. Rev., 64, 1-64.

Nogueira F.T.S., Borecky J., Vercesi A.E., Arruda P., 2005. Genomic structure and regulation of mitochondrial uncoupling protein genes in mammals and plants. Biosci. Rep., 25, 209-226.

Nubel T., Ricquier D., 2006. Respiration under control of uncoupling proteins: Clinical Perspective. Horm. Res., 65, 300-310.

Oberkofler H., Liu Y.M., Esterbauer H., Hell E., Krempler F., Patsch W., 1998. Uncoupling protein-2 gene: reduced mRNA expression in intraperitoneal adipose tissue of obese humans. Diabetologia, 41, 940-946.

Oberkofler H., Iglseder B., Klein K., Unger J., Haltmayer M., Krempler F., Paulweber B., Patsch W., 2005. Associations of the UCP2 gene locus with asymptomatic carotid atherosclerosis in middle-aged women. Arterioscler Thromb. Vasc. Biol., 25, 604-610.

Palmieri F., 2004. The mitochondrial transporter family SLC25: physiological and pathological implications. Pflugers Arch., 447, 689709 .

Pecqueur C., Alves-Guerra M.C., Gelly C., Levi-Meyrueis C., Couplan E., Collin S., Ricquier D., Bouillaud F., Miroux B., 2001. Uncoupling protein 2, in vivo distribution, induction upon oxidative stress, and evidence for translational regulation. J. Biol. Chem., 276, 8705-8712.

Porter R.K., 2006. A new look at UCP 1. Biochim. Biophys. Acta (sous presse).

Raimbault S., Dridi S., Denjean F., Lachuer J., Couplan E., Bouillaud F., Bordas A., Duchamp C., Taouis M., Ricquier D., 2001. An uncoupling protein homologue putatively involved in facultative muscle thermogenesis in birds. Biochem. J., 353, 441-444.

Rial E., Gonzalez-Barroso M., Fleury C., Iturrizaga S., Sanchis D., Jimenez-Jimenez J., Ricquier D., Goubern M., Bouillaud F., 1999. Retinoids activate proton transport by the uncoupling proteins UCP1 and UCP2. EMBO J., 18, $5827-5833$.

Rial E., Aguirregoitia E., Jimenez-Jimenez J., Ledesma A., 2004. Alkylsulfonates activate the uncoupling protein UCP1, implications for the transport mechanism. Biochim. Biophys. Acta, $1608,122-130$.

Ricquier D., Kader J.C., 1976. Mitochondrial protein alteration in active brown fat, a sodium dodecyl sulfalte-polyacrylamide gel electrophoresis study. Biochem. Biophys. Res. Commun., 73, 577-583.

Rolfe D.F., Brand M.D., 1996. Contribution of mitochondrial proton leak to skeletal muscle respiration and to standard metabolic rate. Am. J. Physiol., 271, C1380-C1389.
Roussel D., Harding M., Runswick M.J., Walker J.E., Brand M.D., 2002. Does any yeast mitochondrial carrier have a native uncoupling protein function? J. Bioenerg. Biomembr., 34, 165-176.

Samec S., Seydoux J., Dulloo A.G., 1998 Role of UCP homologues in skeletal muscles and brown adipose tissue, mediators of thermogenesis or regulators of lipids as fuel substrate? FASEB J., 12, 715-724.

Sanchis D., Fleury C., Chomiki N., Goubern M., Huang Q., Neverova M., Grégoire F., Easlick J., Raimbault S., Levi-Meyrueis C., Miroux B., Collins S., Seldin M., Richard D., Warden C., Bouillaud F., Ricuier D., 1998. BMPC1, a novel mitochondrial carrier with high expression in the central nervous system of humans and rodents, and respiration uncoupling activity in recombinant yeast. J. Biol. Chem., 51, 34611-34615.

Schrauwen P., Xia J., Bogardus C., Pratley R.E., Ravussin E., 1999. Skeletal muscle uncoupling protein 3 expression is a determinant of energy expenditure in Pima Indians. Diabetes, 48, 146-149.

Schrauwen P., Saris W.H., Hesselink M.K., 2001. An alternative function for human uncoupling protein 3: protection of mitochondria against accumulation of nonesterified fatty acids inside the mitochondrial matrix. FASEB J., 15, 2497-2502.

Schrauwen P., Hesselink M.K., Vaartjes I., Kornips E., Saris W.H., Giacobino J.P., Russell A., 2002. Effect of acute exercise on uncoupling protein 3 is a fat metabolism-mediated effect. Am. J. Physiol. Endocrinol. Metab., 282, E11-E17.

Schrauwen P., Hoeks J., Schaart G., Kornips E., Binas B., Van De Vusse G.J., Van Bilsen M., Luiken J.J., Coort S.L., Glatz J.F., Saris W.H., Hesselink M.K., 2003. Uncoupling protein 3 as a mitochondrial fatty acid anion exporter. FASEB J., 17, 2272-2274.

Schrauwen P., Hoeks J., Hesselink M.K.C., 2006a. Putative function and physiological relevance of the mitochondrial uncoupling protein 3 : involvement in fatty acid metabolism? Prog. Lipids Res., 45, 17-41.

Schrauwen P., Mensink M., Schaart G., Moonen-Kornips E., Sels J.P., Blaak E.E., Russell A.P., Hesselink M.K., 2006b. Reduced skeletal muscle uncoupling protein-3 content in prediabetic subjects and type 2 diabetic patients: restoration by rosiglitazone treatment. J. Clin. Endocrinol. Metab., 91, 1520-1525.

Sears I.B., MacGinnitie M.A., Kovacs L.G., Graves R.A., 1996. Differentiation dependent expression of the brown adipocyte uncoupling protein gene: regulation by peroxysome proliferators activated gamma receptor. Mol. Cell Biol., $16,3410-3419$.

Shabalina I.G., Jacobsson A., Cannon B., Nedergaard J., 2004. Native UCP1 displays simple competitive kinetics between the regulators purine nucleotides and fatty acids. J. Biol. Chem., 279, 38236-38248.

Shen H., Qi L., Tai E.S., Chew S.K., Tan C.E., Ordovas J.M., 2006. Uncoupling protein 2 promoter polymorphism -866G/A central adiposity, and metabolic syndrome in asians. Obesity, 14, 656-661.

Silva J.E., Rabelo R., 1997. Regulation of the uncoupling protein gene expression. Eur. J. Endocrinol., 136, 251-64.

Skulachev V.P., 1991. Hypothesis. Fatty acid circuit as a physiological mechanism of uncou- 
pling of oxidative phosphorylation. FEBS Lett., 294, 158-162.

Skulachev V.P., 1999. Anion carriers in fatty acid mediated physiological uncoupling. J. Bioenrg. Biomembr., 31, 431-445.

Sluse F.E., Jarmuszkiewicz W., Navet R., Douette P., Mathy G., Sluse-Goffart C.M., 2006. Mitochondrial UCP: New insights into regulation and impact. Biochim Biophys Acta (sous presse)

Sokolova I.M., Sokolov E.P., 2005. Evolution of mitochondrial uncoupling proteins, novel invertebrate UCP homologues suggest early evolutionary divergence of the UCP family. FEBS Lett., 579, 313-317.

Solanes G., Vidal-Puig A., Grujic D., Flier J.S., Lowell B.B., 1997. The human uncoupling protein-3 gene. Genomic structure, chromosomal localization, and genetic basis for short and long form transcripts. J. Biol. Chem., 272, 25433-25436.

Solanes G., Pedraza N., Iglesias R., Giralt M., Villarroya F., 2003. Functional relationship between MyoD and peroxisome proliferators activated receptor dependant regulatory pathways in the control of the human uncoupling protein 3 gene transcription. Mol. Endocrinol., 17, 19441958

Solanes G., Pedraza N., Calvo V., Vidal-Puig A., Lowell B.B.,Villarroya F., 2005. Thyroid hormones directly activate the expression of the human and mouse uncoupling protein 3 genes through a thyroid response element in the proximal promoter region. Biochem. J., 386, 505-513.

Speakman J.R., Talbot D.A.,Selman C., Snart S., McLaren J.S., Redman P., Krol E., Jackson D.M., Johnson M.S., Brand M.D., 2004. Uncoupled and surviving, individual mice with high metabolism have greater mitochondrial uncoupling and live longer. Aging cell, 3, 87-85.

Srivastava A., Rock C., Zhang K., Ruan M., Bolander M.E., Sarkar G., 2006. Expression of a novel alternatively spliced UCP-2 transcript in osteogenic sarcoma. J. Orthop. Sci., 11, 51-57.

Starkov A.A., 2006. Protein-mediated energydissipating pathways in mitochondria. Chem Biol Interact., 161, 57-68.

Stuart J.A., Harper J.A., brindle K.M., Jekabsons M.B., Brand M.D., 2001. Physiological levels of mammalian uncoupling protein 2 do not uncouple yeast mitochondria. J. Biol. Chem., 276, 18633-18639.

Talbot D.A., Hanuise N., Rey B., Rouanet J.L., Duchamp C., Brand M.D., 2003. Superoxide activates a GDP-sensitive proton conductance in skeletal muscle mitochondria from king penguin Aptenodytes patagonicus.
Biochem. Biophys. Res. Commun., 3124, 983988.

Talbot D.A., Duchamp C., Rey B., Hanuise N., Rouanet J.L., Sibille B., Brand M.D., 2004. Uncoupling protein and ATP/ADP carrier increase mitochondrial proton conductance after cold adaptation of king penguins. J. Physiol., $558,123-135$.

Tan M.G.K., Ooi L.L.P.J., Aw S.E., Hui K.M., 2004. Cloning and identification of hepatocellular carcinoma down regulated mitochondrial carrier protein, a novel liver specific uncoupling protein. J. Biol. Chem., 43, 45235-45244.

Tomas P., Jimenez-Jimenez J., Zaragoza P., Vuligonda V., Chandraratna R.A., Rial E., 2004. Activation by retinoids of the uncoupling protein UCP1. Biochim. Biophys. Acta, 1658, 157-164.

Toyomizu M., Ueda M., Sato S., Seki Y., Sato K., Akiba Y., 2002. Cold-induced mitochondrial uncoupling and expression of chicken UCP and ANT mRNA in chicken skeletal muscle. FEBS Lett., 5292-3., 313-318.

$\mathrm{Tu}$ N., Chen H., Winnikes U., Reinert I., Marmann G., Pirke K.M., Lentes K.U., 1999. Structural organization and mutational analysis of the human uncoupling protein 2 (hUCP2) gene. Life Sci., 64, 41-50.

Tu N., Chen H., Winnikes U., Reinert I., Pirke K.M., Lentes K.U 2000. Functional characterization of the 5' flanking and the promoter region of the human UCP3 (hUCP3) gene. Life Sci., 67, 2267-2279.

Vianna C.R., Hagen T., Zhang C.Y., Bachman E., Boss O., Gereben B., Moriscot A.S., Lowell B.B., Bicudo J.E., Bianco A.C., 2001. Cloning and functional characterization of an uncoupling protein homolog in hummingbirds. Physiol. Genomics, 53, 137-145.

Vidal-Puig A., Rosenbaum M., Considine R.C., Leibel R.L., Dohm G.L., Lowell B.B., 1999. Effects of obesity and stable weight reduction on UCP2 and UCP3 gene expression in humans. Obes. Res., 7, 133-140.

Vidal-Puig A.J., Grujic D., Zhang C.Y., Hagen T., Boss O., Ido Y., Szczepanik A., Wade J., Mootha V., Cortright R., Muoio D.M., Lowell B.B., 2000. Energy metabolism in uncoupling protein 3 gene knockout mice. J. Biol. Chem., $275,16258-16266$

Vogler S., Goedde R., Miterski B., Gold R., Kroner A., Koczan D., Zettl U.K., Rieckmann P., Epplen J.T., Ibrahim S.M., 2005. Association of common polymorphism in the promoter of UCP2 with susceptibility to multiple sclerosis. J. Mol. Med., 83, 806-811.

Vogler S., Pahnke J., Rousset S., Ricquier D., Moch H., Miroux B., Ibrahim S.M., 2006.
Uncoupling protein 2 has protective function during experimental autoimmune encephalomyelitis. Am. J. Pathol., 168, 1570-1575.

Walder K., Norman R.A., Hanson R.L., Schrauwen P., Neverova M., Jenkinson C.P. Easlick J., Warden C.H., Pecqueur C., Raimbault S., Ricquier D., Silver M.H., Shuldiner A.R., Solanes G., Lowell B.B., Chung W.K., Leibel R.L., Pratley R., Ravussin E. 1998. Association between uncoupling protein polymorphisms (UCP2-UCP3) and energy metabolism/obesity in Pima indians. Hum. Mol. Genet., 7, 14311435.

Wang Y.X., Lee C.H., Tiep S., Yu R.T., Ham J., Kang H., Evans R.M., 2003. Peroxisome proliferators activated receptor delta activates fat metabolism to prevent obesity. Cell, 113, 159170.

Weigle D.S., Selfridge L.E., Schwartz M.W., Seeley R.J., Cummings D.E., Havel P.J., Kuijper J.L., BeltrandelRio H., 1998. Elevated free fatty acids induce uncoupling protein 3 expression in muscle: a potential explanation for the effect of fasting. Diabetes, 47, 298-302.

Wolkow C.A., Iser W.B., 2006. Uncoupling protein homologs may provide a link between mitochondria, metabolism and lifespan. Ageing Res. Rev., 5, 196-208.

Yoshitomi H., Yamazaki K., Tanaka I., 1999. Mechanism of ubiquitous expression of mouse uncoupling protein 2 mRNA: control by cisacting DNA element in 5' flanking region. Biochem. J., 340, 397-404.

Zackova M., Skobisova E., Urbankova E., Jezek P., 2003. Activating omega-6 polyunsaturated fatty acids and inhibitory purine nucleotides are high affinity ligands for novel mitochondrial uncoupling proteins UCP2 and UCP3. J. Biol. Chem., 278, 20761-20769.

Zhang C.Y., Hagen T., Mootha V.K., Slieker L.J., Lowell B.B., 1999. Assessment of uncoupling activity of uncoupling protein 3 expressed in yeast cells. FEBS Lett., 449, 129-134.

Zhang C.Y., Baffy G., Perret P., Krauss S., Peroni O., Grujic D., Hagen T., Vidal-Puig A.J., Boss O., Kim Y.B., Zheng X.X., Wheeler M.B., Shulman G.I., Chan C.B., Lowell B.B., 2001. Uncoupling protein-2 negatively regulates insulin secretion and is a major link between obesity, beta cell dysfunction, and type 2 diabetes. Cell, 105, 745-755

Zhang M., Wang B., Ni Y.H., Liu F., Fei L., Pan X.Q., Guo M., Chen R.H., Guo X.R., 2006. Overexpression of uncoupling protein 4 promotes proliferation and inhibits apoptosis and differentiation of preadipocytes. Life Sci. (sous presse).

\section{Résumé}

La première protéine découplante identifiée dans le tissu adipeux brun des mammifères, UCP1, est une protéine de la membrane interne mitochondriale qui dissipe l'énergie libérée par l'oxydation des nutriments au détriment de la synthèse d'ATP. Son rôle physiologique dans la thermogenèse est clairement établi. Elle est indispensable au maintien de la température corporelle des animaux hibernants et des nouveaux nés. Chez les mammifères, d'autres protéines homologues, ont par la suite été identifiées dans le muscle (UCP2 et UCP3) tandis que l'on ne connaît à ce jour qu'une seule protéine découplante chez l'oiseau domestique. L'intérêt pour ces protéines a été renforcé car elles semblent, à l'image d'UCP1, responsables d'une fuite de protons au travers de la membrane mitochondriale interne et pourraient jouer un rôle clé dans l'étiologie de nombreuses pathologies. Cependant, les mécanismes mis en jeu sont encore controversés et la fonction physiologique de ces protéines n'est aujourd'hui toujours pas établie: rôle thermogénique, rôle anti-obésité, stress oxydatif, prévention contre la production de radicaux libres? 


\begin{abstract}
What is the role of mitochondrial uncoupling proteins in mammals and birds?

The first uncoupling protein (or UCP), identified in brown adipose tissues of Mammals, UCP1, is a transporter from the internal mitochondrial membrane, that dissipates the energy from nutrient oxidations by decreasing the rate of ATP synthesis. Its physiological role in thermogenesis is clearly established, since UCP1 is necessary to maintain body temperature in newborn and hibernating animals. Other uncoupling protein homologues have also been identified in the muscles of Mammals (UCP2 and UCP3), but only one uncoupling protein has been evidenced in birds yet. The interest for these proteins was enhanced recently since they seem to be involved in the proton leak through the internal mitochondrial membrane as UCP1. Thus, they could play a role in the development of several pathologies. However, the mechanisms involved are still debated and the physiological function of these proteins is not completely clarified: a role in thermogenesis, in limiting the generation of reactive oxygen species, against obesity or oxidative damage?
\end{abstract}

DAMON M., COLLIN A., 2006. Quel est le rôle des protéines découplantes mitochondriales chez les mammifères et les oiseaux ? INRA Prod. Anim., 19, 287-304. 
